\title{
Astrocyte NMDA receptors' activity sustains neuronal survival through a Cdk5-Nrf2 pathway
}

\author{
D Jimenez-Blasco ${ }^{1,2}$, P Santofimia-Castaño ${ }^{3}$, A Gonzalez ${ }^{3}$, A Almeida ${ }^{1,2}$ and JP Bolaños ${ }^{\star, 1,2}$
}

Neurotransmission unavoidably increases mitochondrial reactive oxygen species. However, the intrinsic antioxidant defense of neurons is weak and hence the mechanism whereby these cells are physiologically protected against oxidative damage is unknown. Here we found that the antioxidant defense of neurons is repressed owing to the continuous protein destabilization of the master antioxidant transcriptional activator, nuclear factor-erythroid 2-related factor-2 (Nrf2). By contrast, Nrf2 is highly stable in neighbor astrocytes explaining their robust antioxidant defense and resistance against oxidative stress. We also show that subtle and persistent stimulation of $\mathrm{N}$-methyl-D-aspartate receptors (NMDAR) in astrocytes, through a mechanism not requiring extracellular $\mathrm{Ca}^{2+}$ influx, upregulates a signal transduction pathway involving phospholipase $\mathrm{C}$-mediated endoplasmic reticulum release of $\mathrm{Ca}^{2+}$ and protein kinase $\mathrm{C} \delta$ activation. Active protein kinase $\mathrm{C} \delta$ promotes, by phosphorylation, the stabilization of p35, a cyclin-dependent kinase-5 (Cdk5) cofactor. Active p35/Cdk5 complex in the cytosol phosphorylates Nrf2 at Thr ${ }^{395}, \mathrm{Ser}^{433}$ and Thr ${ }^{439}$ that is sufficient to promote Nrf2 translocation to the nucleus and induce the expression of antioxidant genes. Furthermore, this Cdk5-Nrf2 transduction pathway boosts glutathione metabolism in astrocytes efficiently protecting closely spaced neurons against oxidative damage. Thus, intercellular communication through NMDAR couples neurotransmission with neuronal survival. Cell Death and Differentiation (2015) 22, 1877-1889; doi:10.1038/cdd.2015.49; published online 24 April 2015

It is widely accepted that glutamatergic neurotransmission increases mitochondrial $\mathrm{Ca}^{2+}$ uptake, which enhances reactive oxygen species (ROS) responsible for oxidative damage and neurodegeneration. ${ }^{1,2}$ To defend themselves against ROS, neurons actively oxidize glucose through the pentosephosphate pathway (PPP), a metabolic route providing the $\operatorname{NADPH}\left(\mathrm{H}^{+}\right)$that is necessary for the regeneration of reduced glutathione (GSH) from its oxidized form (GSSG). ${ }^{3,4}$ To achieve this, neurons keep inhibited the glycolytic pathway by continuously degrading the key glycolytic-promoting enzyme, 6-phosphofructo-2-kinase/fructose-2,6-bisphosphatase-3 (PFKFB3) by the action of the E3 ubiquitine ligase anaphase-promoting complex/cyclosome and its cofactor Cdh1 (APC/C-Cdh1). ${ }^{4}$ Although this strategy provides defense to neurons under resting conditions, the level of antioxidant protection under stressing conditions is transient and weak. ${ }^{4}$ Thus, during activation of the synaptic ionotropic glutamate receptors, particularly the $\mathrm{N}$-methyl-D-aspartate receptors (NMDAR) subtypes, neurons inhibit the FOXO target gene thioredoxin inhibitor Txnip hence increasing their antioxidant defenses. ${ }^{5}$ However, overactivation of NMDAR in neurons, an excitotoxic phenomenon that underlies the pathogenesis of a number of neurological disorders, including
Alzheimer's disease, Amyotrophic Lateral Sclerosis or stroke, ${ }^{1,2}$ concomitantly inhibits the ubiquitylating activity of APC/C-Cdh1 (ref. 6) leading to PFKFB3 stabilization, glycoIytic activation and PPP inhibition. ${ }^{7}$ This metabolic reprograming caused by NMDAR activation compromises the efficacy of the antioxidant defense of neurons causing apoptotic death, at least when neurons are cultured alone. ${ }^{7}$ Therefore, neurons should be provided with additional mechanism(s) aiding to combat the excess ROS they are continuously exposed.

Astrocytes are active players in neural signaling by efficiently removing excess glutamate at the synapse and modulating neurotransmission. ${ }^{8}$ These glial cells are also essential for neuronal survival as they provide neurons with energy oxidative precursors, such as lactate. ${ }^{9-11}$ Astrocytes are able to release GSH precursors, which neurons can use for the de novo GSH biosynthesis. ${ }^{12}$ Accordingly, the presence of astrocyte cells surrounding neurons seems to be critical to keep neuronal functions, including neurotransmission, nutrients supply and antioxidant defense. However, the molecular mechanism that explains the extreme neuronal vulnerability to oxidative damage, as well as the mode whereby neurons dictates astrocytes to supply antioxidant protection, are unknown. The nuclear factor-erythroid

\footnotetext{
${ }^{1}$ Institute of Functional Biology and Genomics (IBFG), University of Salamanca-CSIC, 37007 Salamanca, Spain; ${ }^{2}$ Institute of Biomedical Research of Salamanca (IBSAL), University Hospital of Salamanca, 37007 Salamanca, Spain and ${ }^{3}$ Department of Physiology, Faculty of Veterinary, University of Extremadura, 10003 Caceres, Spain ${ }^{*}$ Corresponding author: JP Bolaños, Institute of Functional Biology and Genomics (IBFG), University of Salamanca-CSIC, Zacarias Gonzalez, 2, Salamanca 37007, Spain. Tel: +34 9232949 07; Fax: +34 9232248 76; E-mail: jbolanos@usal.es

Abbreviations: 7-AAD, 7-amino-actinomycin D; ActD, Actinomycin D; AMPA, $\alpha$-amino-3-hydroxy-5-methyl-4-isoxazolepropionic acid; Cdk5, cyclin-dependent kinase-5; CNQX, 6-cyano-7- nitroquinoxaline-2,3-dione; DAG, Diacylglicerol; DAPI, 4',6-diamidino-2-phenylindole; EDTA, Ethylenediaminetetraacetic acid; EGTA, ethylene glycol tetraacetic acid; ER, endoplasmatic reticulum; Gfap, Glial Fibrilliary Acidic Protein; GFP, Green fluorescent protein; Ho-1, Heme- oxygenase-1; Keap1, Kelch-like ECHassociated protein 1; Map2, Microtubule-Associated Protein 2; NMDAR, N-methyl-D-aspartate receptors; Nq01, NADPH quinone oxidorreductase-1; Nrf2, nuclear factorerythroid 2-related factor-2; PBS, Phosphate-buffered saline; PEI, Polyethylenimine; PFKFB3, 6-phosphofructo-2- kinase/fructose-2,6-bisphosphatase-3; PKC $\delta$, Protein kinase C 8 ; PLC, Phospholipase C; PPP, pentose-phosphate pathway; Rbx1, RING-box protein 1; ROS, reactive oxygen species; RT-qPCR, Quantitative reverse transcription-polymerase chain reaction; S.E.M., Standard error of the mean; Tps, thapsigargin

Received 02.9.14; revised 07.3.15; accepted 23.3.15; Edited by M Deshmukh; published online 24.4.15
} 
2-related factor-2 (Nrf2) is a master transcription factor that coordinates the cell antioxidant machinery. ${ }^{13}$ However, whether Nrf2 has a function in astrocyte-mediated neuronal protection is a matter of debate. ${ }^{14-18}$ Like postsynaptic neurons, astrocytes express ionotropic glutamate-receptor subtype NMDAR, ${ }^{19}$ although their precise function in these glial cells is still enigmatic. In view that excess NMDAR activity, by inhibiting APC/C-Cdh1 in neurons, ${ }^{6}$ leads to oxidative damage, $^{7}$ we sought to investigate whether astrocyte NMDAR, by sensing neurotransmission, would support neuronal survival. We found that Nrf2 is highly unstable in neurons due to continuous protein destabilization, which explains their high vulnerability to oxidative stress. Moreover, we showed that NMDAR activity in astrocytes boost a signaling pathway involving p35/Cdk5-mediated Nrf2 phosphorylation and activation that stimulates the release of GSH precursors for neuronal de novo GSH biosynthesis, hence sustaining neuronal antioxidant protection and survival.

\section{Results}

High Nrf2 destabilization explains weak antioxidant defense of neurons. To investigate Nrf2 regulation in brain cells, we first analyzed Nrf2 mRNA and protein levels, which were higher in primary astrocytes than in neurons of the rat cortex (Figures 1a and b; Supplementary Figure 1a). Nrf2 is repressed by Kelch-like ECH-associated protein 1 (Keap1)Cullin 3 (Cul3)-RING-box protein 1 (Rbx1), an E3 ubiquitin ligase that targets Nrf2 for proteasomal degradation. ${ }^{13} \mathrm{Cul} 3$ and Keap1 protein levels (Figure 1b; Supplementary Figure 1a), as well as Cul3 mRNA (Supplementary Figure 1b) were higher in neurons than in astrocytes. As Cul3 is transcriptionally regulated by the signalosome, ${ }^{20}$ we next analyzed the mRNA levels of the signalosome catalytic subunit Cop9S5, and those of the Cul3 assembly factor Cand1 (ref. 21) in neurons and astrocytes. As Cop9S5 and Cand1 mRNA levels were found similarly expressed in both cell types (Supplementary Figures 1c and d), a differential signalosome expression would unlikely explain the differences in Cul3 mRNA and Cul3 protein abundances in neurons versus astrocytes. We then sought to investigate whether the observed high Cul3 levels, by promoting Nrf2 degradation, explains the low Nrf2 protein abundance in neurons. Knocking down Cul3 by RNA interference led to Nrf2 stabilization in astrocytes (Figure 1c; Supplementary Figure 1e) and in neurons (Figure 1d; Supplementary Figure 1f). Thus, despite their considerably low abundance of Nrf2 mRNA, neurons translate it and subsequently degrade it. Accordingly, the relative abundances of Nrf2-target antioxidant genes glutamate-cysteine ligase, catalytic subunit $(G c / c)$ and hemeoxygenase-1 (Ho-1) were lower in neurons than in astrocytes (Figure 1e). Knocking down Cul3 in neurons accumulated Nrf2 protein to levels similar to those found in astrocytes (Figure 1f; Supplementary Figure 1g), but their targets Gclc and Ho-1 mRNA levels did not (Figure 1g). Inhibition of the proteasome with MG132 stabilized Nrf2 in astrocytes (Figure 1h; Supplementary Figure 1h) and in neurons (Figures 1i-k; Supplementary Figures 1i-l). These results show that, whereas neurons are equipped with a discrete
Nrf2-regulated antioxidant system, the efficacy of its response is weak and inefficient when compared with that of astrocytes, suggesting the contribution of alternative mechanisms in neuroprotection.

NMDAR activity promotes functional activation of Nrf2 in astrocytes. We next sought to investigate whether astrocytes, through NMDAR, would sense glutamatergic neurotransmission to contribute in neuronal antioxidant defense. To test this hypothesis, astrocytes were incubated with low NMDA concentrations likely mimicking NMDAR physiological signaling. NMDA dose-dependently $(1-100 \mu \mathrm{M})$ triggered a delayed, but sustained rise in cytosolic free $\mathrm{Ca}^{2+}$ concentration $\left(\left[\mathrm{Ca}^{2+}\right]_{\mathrm{c}}\right)$ in astrocytes (Figure 2a). Although the occurrence of NMDAR in astrocytes has been debated, ${ }^{19,22}$ the constitutive expression of all NMDAR subunits, at different levels, including Nr1, Nr2a, Nr2b, Nr2c, Nr2d, Nr3a and Nr3b has been widely documented. ${ }^{23-25}$ Likewise, we show that Nr1a, Nr2a and Nr2b mRNA (Supplementary Figure 1m) and $\mathrm{Nr} 2 \mathrm{a}$ and Nr2b protein (Supplementary Figure 1n) are expressed in astrocytes under our circumstances. As from $50 \mu \mathrm{M}, \mathrm{NMDA}$ is considered neurotoxic, ${ }^{5,26}$ we used $20 \mu \mathrm{M}$ NMDA thereafter as it triggered a similar $\left[\mathrm{Ca}^{2+}\right]_{\mathrm{c}}$ response (Figure $2 \mathrm{a}$ ) otherwise resembling physiologic-, in contrast to excitotoxic-like neurotransmission. The delayed feature in $\left[\mathrm{Ca}^{2+}\right]_{\mathrm{c}}$ signal (Figure 2a) would likely be due to the low $\mathrm{Ca}^{2+}$ permeability of NMDAR in astrocytes, as previously described. ${ }^{27}$ Furthermore, incubation of astrocytes with NMDA $(20 \mu \mathrm{M})$ in the absence of extracellular $\mathrm{Ca}^{2+}\left(\left[\mathrm{Ca}^{2+}\right]_{\text {e.c. }}=0\right)$ revealed increased $\left[\mathrm{Ca}^{2+}\right]_{\mathrm{c}}$ during a limited period, after which the sarco-ER $\mathrm{Ca}^{2+}$-ATPase inhibitor, thapsigargin, had no effect (Figure 2b), suggesting that the main source of cytosolic free $\mathrm{Ca}^{2+}$ is the endoplasmic reticulum (ER), not the extracellular space. In fact, incubation of astrocytes under $\left[\mathrm{Ca}^{2+}\right]_{\text {e.c. }}=0$ with thapsigargin in the absence of NMDA robustly increased $\left[\mathrm{Ca}^{2+}\right]_{\mathrm{c}}$ transiently, after which addition of NMDA had no effect on $\left[\mathrm{Ca}^{2+}\right]_{c}$ (Figure $2 \mathrm{c}$ ). These data indicate that the occurrence of the delayed increased $\left[\mathrm{Ca}^{2+}\right]_{\mathrm{C}}$ in NMDA-treated astrocytes has an ER origin. To further confirm that the observed intracellular $\mathrm{Ca}^{2+}$ signal was a consequence of NMDAR activation, the natural NMDAR agonist, glutamate, was used. As shown in Supplementary Figure 2, glutamate was able to increase $\left[\mathrm{Ca}^{2+}\right]_{\mathrm{C}}$ in a manner that was prevented by MK801, a specific NMDAR antagonist, but not by CNQX (6-cyano-7-nitroquinoxaline-2,3-dione), an AMPA/kainate receptor antagonist. Thus, astrocytes express functional NMDA receptors, the activation of which transduces a signaling mechanism leading to ER-derived cytosolic $\mathrm{Ca}^{2+}$ increase. Astrocytes in culture often contain traces of other neural cell types, including neurons, microglia and oligodendrocytes that might putatively account for the observed NMDAR-mediated changes in free cytosolic $\mathrm{Ca}^{2+}$. However, all our experiments were performed in astrocytes that were reseeded after overnight shaking to remove loosely attached cells, such as neurons (Map2 ${ }^{+}$), microglia (lba ${ }^{+}$) and oligodendrocytes $\left(\mathrm{O}^{+}\right.$; Supplementary Figures $3 a$ and $\left.\mathrm{b}\right)$, hence yielding a highly enriched astrocyte preparation exclusively responsible for the observed NMDAR-mediated responses. 

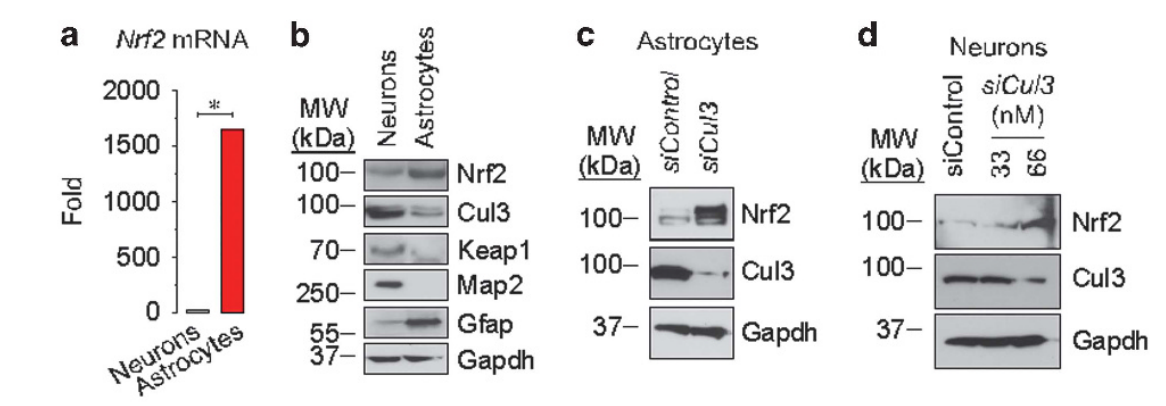

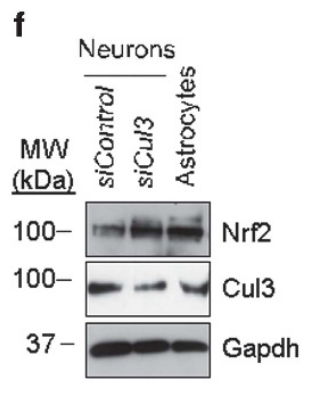

g

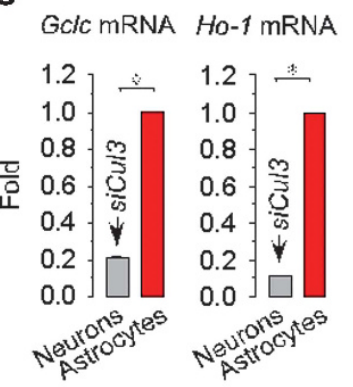

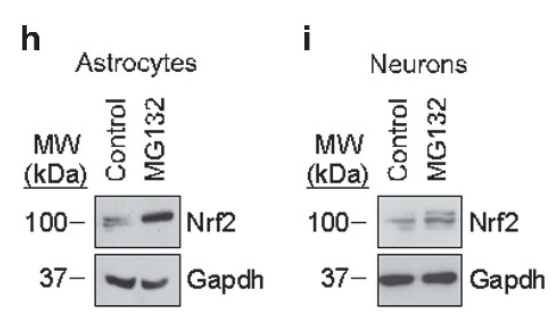
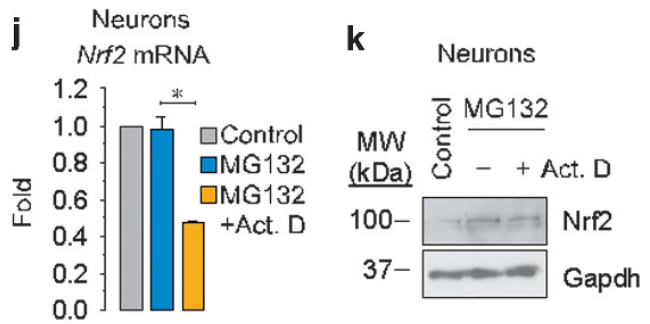

Figure 1 Higher Nrf2 protein destabilization rate in neurons when compared with astrocytes explains low Nrf2 functional abundance in neurons. (a) Quantitative real-time PCR (RT-qPCR) analysis of the relative mRNA abundance of Nrf2 in rat cortical primary neurons and rat cortical primary astrocytes; Gapdh mRNA was used for normalization, and the astrocytes data are expressed as the change relative to neurons. Results reveals a $\sim 1600$-fold higher Nrf2 mRNA abundance in astrocytes than in neurons. (b) Western blot analysis indicates lower Nrf2 and higher Cul3 and Keap1 protein abundances in neurons when compared with astrocytes. Map2 and Gfap protein levels indicate the purity of neurons and astrocytes cultures, respectively. Gapdh was used a loading marker. (c) siRNA against Cul3 (siCul3, $100 \mathrm{nM}$ ) leading to decreased Cul3 protein increases Nrf2 abundance in astrocytes; siControl (100 nM) was a siRNA against luciferase. (d) siCul3 treatment dose-dependently (33-66 nM) increases Nrf2 in neurons. (e) RT-qPCR analysis of Nrf2-target genes glutamate-cysteine ligase catalytic subunit (Gclc) and heme-oxygenase-1 (Ho-1) reveals 6- and 40-fold lower mRNA abundances, respectively, in neurons than in astrocytes. (f) siCul3 (66 nM) in neurons increases Nrf2 protein to levels similar to those of the astrocytes. (g) Gclc and Ho-1 mRNA levels in neurons after siCul3 (66 nM) are $\sim 20$ and 10\%, respectively, of those in control astrocytes. (h) The proteasome inhibitor MG132 (20 $\mu \mathrm{M}, 2 \mathrm{~h})$ increased Nrf2 protein abundance in astrocytes. (i) MG132 increased Nrf2 protein abundance in neurons. (j) MG132 did not increase Nrf2 mRNA abundance in neurons, and the transcriptional inhibitor actinomycine D (Act. D; $100 \mathrm{ng} / \mathrm{ml}$ ) decreased Nif2 mRNA levels. (k) The increase in Nrf2 protein levels in neurons by MG132 was unaffected by actinomycine D. Data are expressed as mean \pm S.E.M. ${ }^{\star} P<0.05$ (Student's t-test; $n=3-4$ independent experiments)

Neuronal $\left[\mathrm{Ca}^{2+}\right]_{\mathrm{c}}$ changed similarly with $20 \mu \mathrm{M}$ NMDA (Supplementary Figure $3 \mathrm{c}$ ). Sustained (8h) incubation of astrocytes with NMDA $(20 \mu \mathrm{M})$ upregulated Nrf2-target genes Gclc, Ho-1 and NADPH quinone oxidorreductase-1 (Nqo1; Figure 2d). This was a consequence of NMDA acting on its receptors, as MK801 abolished this effect (Figure 2d). Moreover, this was an Nrf2-dependent process, as Nrf2 knockdown (Figures $2 \mathrm{e}$ and f; Supplementary Figure 3d) prevented the increase in Nrf2-target genes expression (Figure 2g). To further confirm these results, we next assessed Nrf2 protein abundance and subcellular localization after NMDA treatment, and we found an increase (Figure 2h; Supplementary Figure 3e) and nuclear translocation (Figure 2i; Supplementary Figure 3f) of Nrf2. As Nrf2 abundance is considerably higher in astrocytes than in neurons (Figures 1a and b), and in view that primary neurons in culture likely contains traces of astrocytes, we asked whether Nrf2 found in neuronal cultures would be of astrocytic contribution. Flow cytometric analysis of neurons in primary culture revealed an enrichment of $96 \%$ in $\mathrm{Map}^{+}$cells (neurons) and $4 \%$ of $\mathrm{Gfap}^{+}$cells (astrocytes; Supplementary Figure 4a). However, western blotting of proportional amounts of proteins extracted from both cell types (Supplementary Figure $4 \mathrm{~b}$ ) revealed that the 4\% contribution of astrocytes to neuronal cultures does not account for the Nrf2 protein abundance of neurons, both under resting conditions (Supplementary Figure 4b) or after MG132 treatment (Supplementary Figure 4c). Furthermore, neurons were separated from astrocytes by flow cytometric cell sorting, using the plasma membrane astrocytic-specific antibody anti-integrin- $\beta 5$ (Supplementary Figure $4 d$ ). Western blotting of the $\beta 5$-integrin-negative cell subpopulation (astrocyte-free neurons, as revealed by neuron-specific $\beta$ III-tubulin) demonstrated that neurons accounted for the MG132mediated increase in Nrf2 protein (Supplementary Figure 4d). 
a

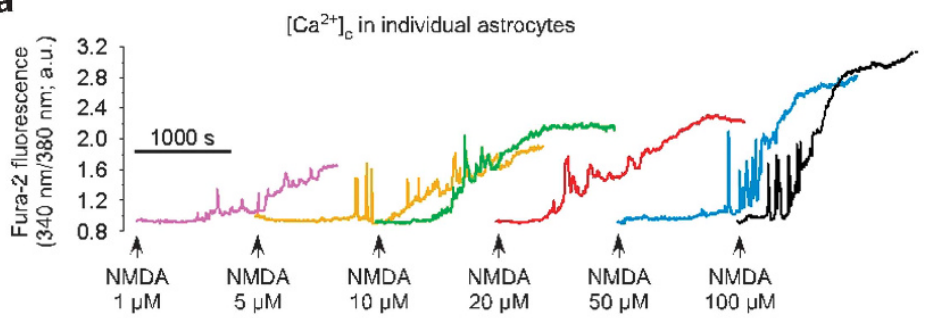

b

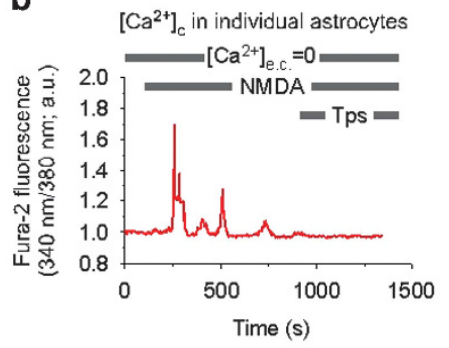

C

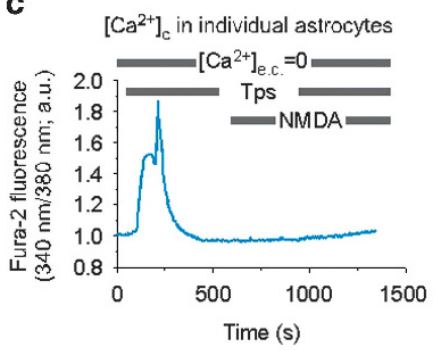

d

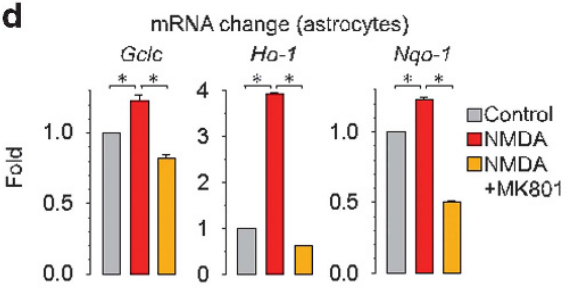

f

e Nif2 mRNA change (astrocytes)

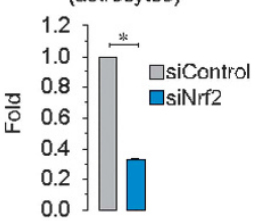

g

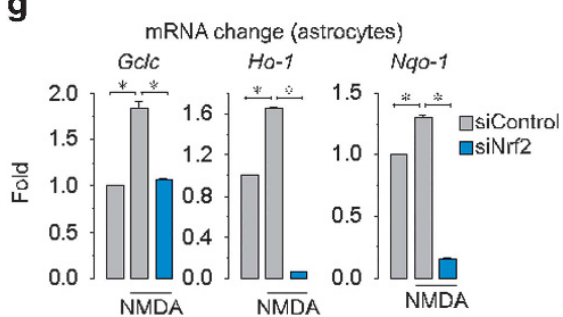

h

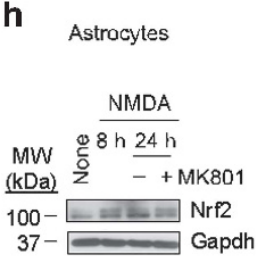

i Astrocytes

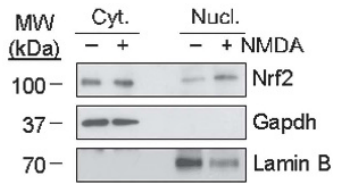

Figure 2 NMDA causes sustained cytosolic $\mathrm{Ca}^{2+}$ rise and Nif2 functional activation in astrocytes. (a) NMDA dose-dependently (1-100 $\left.\mu \mathrm{M}\right)$ induced a delayed and sustained increase in cytosolic free $\mathrm{Ca}^{2+}$ concentrations $\left(\left[\mathrm{Ca}^{2+}\right]_{c}\right)$ in individual astrocytes. (b) Astrocytes were incubated with NMDA $(20 \mu \mathrm{M})$ in the absence of extracellular $\mathrm{Ca}^{2+}\left(\left[\mathrm{Ca}^{2+}\right]_{\text {e.c. }}=0\right)$, which revealed increased $\left[\mathrm{Ca}^{2+}\right]_{\mathrm{c}}$ during a limited period, after which the sarco-ER Ca ${ }^{2+}$-ATPase inhibitor, thapsigargin $(\mathrm{Tps}, 1 \mu \mathrm{M})$, had no effect. (c) Incubation of astrocytes under $\left[\mathrm{Ca}^{2+}\right]_{\text {e.c. }}=0$ with Tps $(1 \mu \mathrm{M})$ in the absence of NMDA robustly increased $\left[\mathrm{Ca}^{2+}\right]_{c}$ transiently, after which addition of NMDA had no effect on $\left[\mathrm{Ca}^{2+}\right]_{\mathrm{c}}$. (d) Incubation of astrocytes with NMDA $(20 \mu \mathrm{M})$ for $8 \mathrm{~h}$ increased Gclc, Ho-1 and NADPH quinone oxidorreductase-1 (Nqo1) mRNA levels, an effect that was abolished by the NMDA antagonist MK801 (10 $\mu \mathrm{M})$. (e) siNrf2 (100 nM, $72 \mathrm{~h}$ ) decreased Nrf2 mRNA levels in astrocytes; siControl (100 nM) was an siRNA against luciferase. (f) siNrf2 decreased Nrf2 protein levels in astrocytes. (g) siNrf2 abolished the NMDA ( $20 \mu \mathrm{M}, 8 \mathrm{~h})$-induced increase in Gclc, Ho-1 and Nqo1 mRNA levels in astrocytes. (h) NMDA (20 $\mu \mathrm{M}$, 8 or $24 \mathrm{~h}$ ) increased Nrf2 protein abundance in astrocytes, and MK801 abolished this effect. (i) NMDA ( $20 \mu \mathrm{M}, 8$ or $24 \mathrm{~h}$ ) increased endogenous Nrf2 levels in the nucleus of astrocytes. Data are expressed as mean \pm S.E.M. ${ }^{*} P<0.05$ (Student's $t$-test for $\mathbf{e}$; ANOVA followed by Bonferroni test for $\mathbf{d}$ and $\mathbf{g} ; n=3-4$ independent experiments)

Altogether, our results show that, although neurons are able to stabilize Nrf2 during proteasomal inhibition, astrocytes account for the vast majority of Nrf2 abundance of these two cell types. Furthermore, we show that subtle NMDAR activation in astrocytes compatible with physiological neurotransmission triggers a functional Nrf2-mediated antioxidant response in astrocytes.

Stimulation of NMDAR promotes Cdk5-mediated Nrf2 phosphorylation and activation. We next aimed to understand the molecular mechanism responsible for the NMDARdependent stimulation of Nrf2 pathway in astrocytes. In view that Nrf2 contains several potential consensus phosphorylation sites by multiples protein kinases (http://scansite.mit.edu/), we asked whether NMDAR activity triggered Nrf2 phosphorylation. Immunoprecipitation of Nrf2 followed by western blotting against an anti-Ser antibody revealed Nrf2 phosphorylation by NMDAR activation both in astrocytes (Figure 3a; Supplementary Figure 5a) and in neurons (Supplementary Figure 5b) that was prevented by MK801 (Figure 3a; Supplementary Figure $5 c$ ). We previously reported that excitotoxic NMDAR activation in neurons triggers $\mathrm{Ca}^{2+}$ mediated, p25-dependent, cyclin-dependent kinase-5 (Cdk5) activation. ${ }^{6}$ Thus, we searched for putative Cdk5 
a

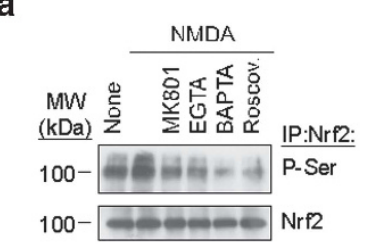

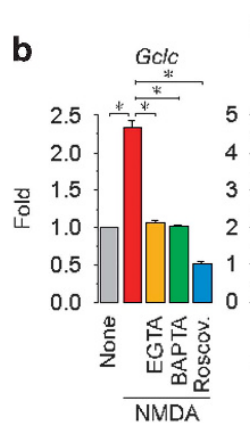

mRNA change

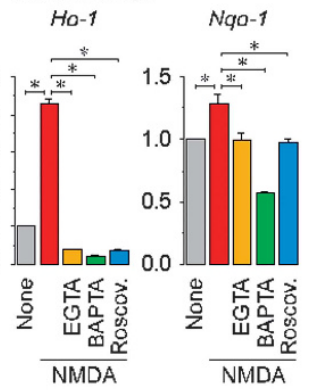

C

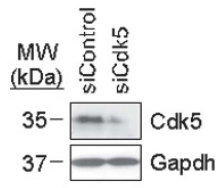

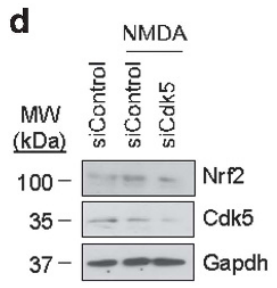
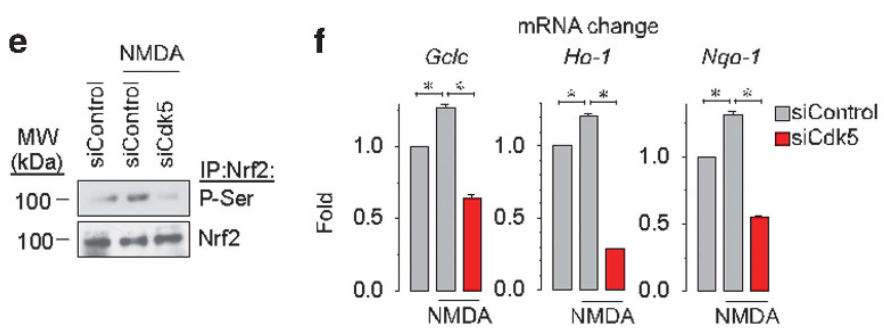

Figure 3 Stimulation of NMDA receptors in astrocytes promotes Cdk5-mediated Nrf2 phosphorylation and activation. (a) Nrf2 immunoprecipitation in astrocytes followed by western blotting against an anti-serine antibody revealed increased Nrf2 phosphorylation by NMDA treatment $(20 \mu \mathrm{M}$ for $8 \mathrm{~h})$, an effect that was prevented by MK801 (10 $\mu \mathrm{M})$, by extracellular $\mathrm{Ca}^{2+}$ chelation with EGTA (100 $\mu \mathrm{M}$ in $\mathrm{Ca}^{2+}$-free medium), by intracellular $\mathrm{Ca}^{2+}$ chelation with BAPTA $(10 \mu \mathrm{M})$ and by the general cyclin-dependent kinase (Cdk) inhibitor roscovitine $(10 \mu \mathrm{M})$. (b) EGTA, BAPTA and roscovitine abolishes NMDA (20 $\mu \mathrm{M}, 8 \mathrm{~h})$-induced increase in the mRNA levels of the Nrf2-target genes Gclc, Ho-1 and Nqo1 in astrocytes. (c) siRNA against Cdk5 (siCdk5, $100 \mathrm{nM} ; 72 \mathrm{~h}$ ) efficiently knocks down Cdk5 in astrocytes; siControl was a siRNA against luciferase. (d) siCdk5 prevents NMDA $(20 \mu \mathrm{M}, 8 \mathrm{~h})$-dependent increase in Nrf2 protein abundance in astrocytes. (e) NMDA $(20 \mu \mathrm{M}, 8 \mathrm{~h})$-induced Nrf2 phosphorylation is prevented by siCdk5 in astrocytes. (f) siCdk5 abolishes NMDA (20 $\mu \mathrm{M}, 8 \mathrm{~h})$-induced increase in the mRNA levels of the Nrf2-target genes Gclc, Ho-1 and Nqo1 in astrocytes. Data are expressed as mean \pm S.E.M. ${ }^{*} P<0.05$ (ANOVA followed by Bonferroni test; $n=3-4$ independent experiments)

consensus motifs in the Nrf2 sequence, and found at least three high-score potential Cdk5-target residues, namely $\mathrm{Thr}^{395}$ (VKQNGPKTPVHSSGD), $\operatorname{Ser}^{433}$ (PEKELPVSPGHRKTP) and $\mathrm{Thr}^{439}$ (VSPGHRKTPFTKDKH; http://scansite.mit.edu/). We therefore hypothesized whether Cdk5 would be responsible for Nrf2-mediated phosphorylation upon NMDAR stimulation. We found that both extracellular and intracellular $\mathrm{Ca}^{2+}$ sequestration, or inhibition of $\mathrm{Cdk}(\mathrm{s})$ by roscovitine, fully abolished Nrf2 phosphorylation in astrocytes (Figure 3a) and in neurons (Supplementary Figures $5 d$ and e), as well as Nrf2-target genes activation in astrocytes (Figure 3b). To test whether Cdk5 mediated these effects, we knocked down Cdk5 in astrocytes (Figure 3c; Supplementary Figure 6a), which prevented NMDAR-dependent increase in Nrf2 protein abundance (Figure 3d; Supplementary Figure 6b). Furthermore, Nrf2 phosphorylation was diminished by Cdk5 knockdown in both astrocytes (Figure 3e; Supplementary Figure $6 c)$ and neurons (Supplementary Figures $6 \mathrm{~d}$ and e). Finally, Cdk5 knockdown abolished the increase in Nrf2-target antioxidant genes expression in astrocytes (Figure 3f). These results indicate that activation of NMDAR in astrocytes promotes Cdk5-mediated Nrf2 phosphorylation leading to its functional activation.

NMDAR-mediated transduction pathway leading to Nrf2 activation in astrocytes. To further get insight into the mechanism whereby NMDAR activates Cdk5 leading to Nrf2 phosphorylation in astrocytes, we first assessed the possible conversion of Cdk5-cofactor, p35, into p25, a phenomenon that we previously reported in neurons during excitotoxicity (100 $\mu \mathrm{M}$ NMDA). ${ }^{6}$ However, we found that neither incubation of astrocytes (Figure 4a; Supplementary Figure 5f) or neurons (Supplementary Figure $5 \mathrm{~g}$ ) with $20 \mu \mathrm{M}$ NMDA resulted in p35 conversion to p25. In agreement with this, $\mathrm{MDL}$, that is, an inhibitor of calpain responsible for p35 breakdown into p25 (ref.28), was unable to prevent NMDARmediated Nrf2 phosphorylation (Figure 4b; Supplementary Figure 6h,i). Thus, physiologic-like stimulation of NMDAR does not promote the p25/Cdk5 activation that takes place during excitotoxicity. ${ }^{6}$ To test whether Cdk5 was active in astrocytes treated with physiologic-like NMDA concentrations, we fractionated nuclei and cytosol, which were subjected to an in vitro Cdk5 activity assay. As shown in Figure 4c (Supplementary Figure 7a), Cdk5-immunoprecipitated cytosol - but not nuclei extracts - was able to phosphorylate histone $\mathrm{H} 1$. This indicates that $\mathrm{Cdk} 5$ remains active in the cytosol, a result consistent with the physiologic p35/Cdk5 activity. ${ }^{29}$ We next performed an in vitro Nrf2 phosphorylation assay by $\mathrm{p} 35 / \mathrm{Cdk} 5$ in either wild-type Nrf2, or in a site-directed T395A/S433A/T439A-mutant Nrf2 form. As depicted in Figure 4d, (Supplementary Figure 7b) p35/ Cdk5 phosphorylated the wild type, but very weakly the T395A/S433A/T439A mutant form of Nrf2 showing that Nrf2 is a p35/Cdk5 substrate, although additional p35/Cdk5phosphorylation site(s) may occur in Nrf2. To investigate the subcellular localization of Nrf2 upon NMDAR activation, we then transfected astrocytes with either wild type or T395A/ S433A/T439A mutant forms of Nrf2 fused with green fluorescent protein (GFP). As shown in Figure $4 \mathrm{e}$ (Supplementary Figure 7c), NMDA induced accumulation of wild type, but not T395A/S433A/T439A mutant Nrf2-GFP. Moreover, we observed that although wild-type Nrf2 was 
accumulated in the cytosol and in the nucleus upon NMDA treatment, the T395A/S433A/T439A Nrf2 mutant did not (Figure 4f; Supplementary Figure 7d). Furthermore, in the absence of NMDA, the phosphomimetic T395D/S433D/ T439D Nrf2 mutant accumulated in the cytosol and in the nucleus of astrocytes, thus mimicking the effect of NMDA on a

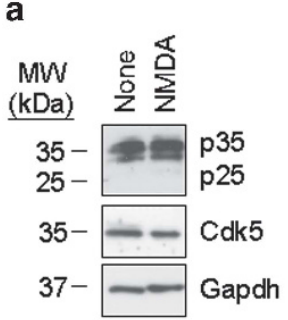

b

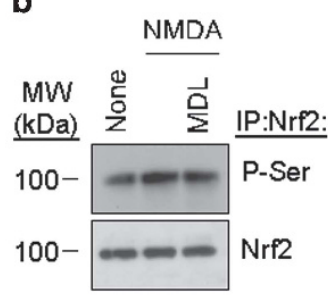

C

MW Cyt. Nucl.

(kDa) ++-+ NMDA

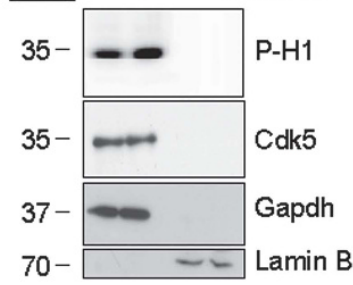

d in vitro Nif2

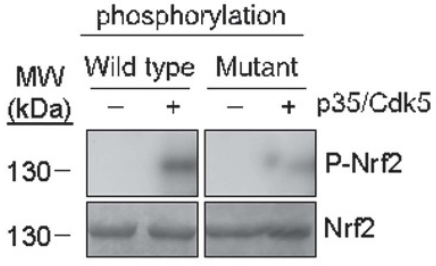

e

MW $\frac{\text { Nrf2-GFP }}{$\cline { 3 - 4 }}

$\underline{(\mathrm{kDa})} \overline{-+}+$ +NMDA

$130--\infty$ GFP

$37-\infty-\infty$ Gapdh

f

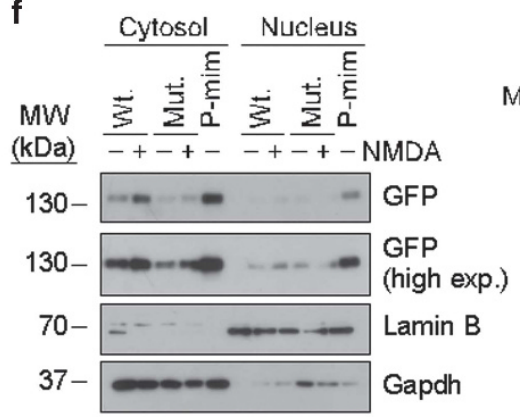

g

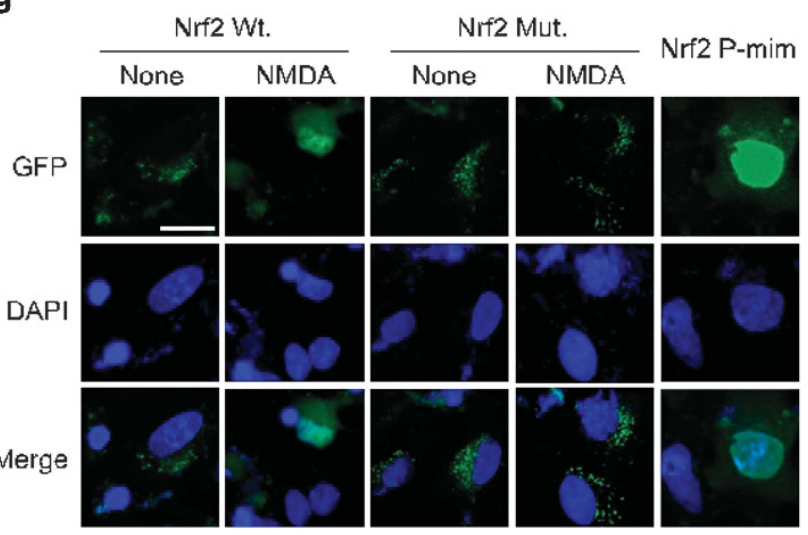

Percentage of astrocytes with nuclear GFP-staining (\%)

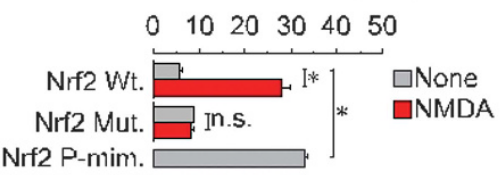

h

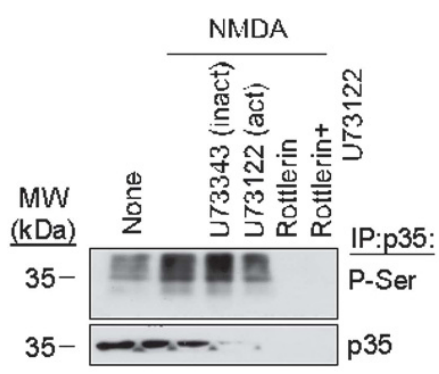

i

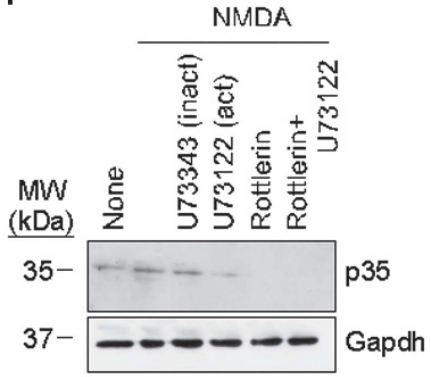

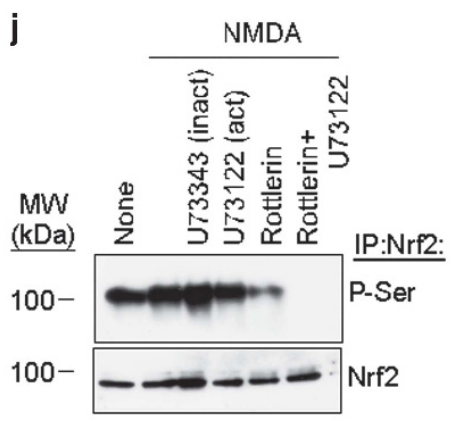

k

$\left[\mathrm{Ca}^{2+}\right]_{c}$ in individual astrocytes

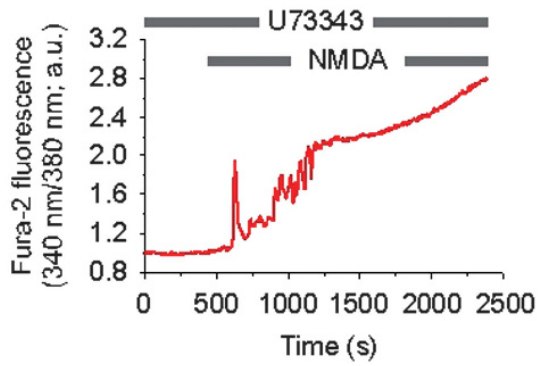

$\left[\mathrm{Ca}^{2+}\right]_{\mathrm{C}}$ in individual astrocytes

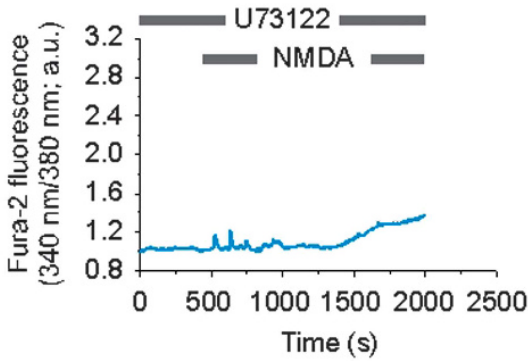


the wild-type Nrf2 (Figure 4f (Supplementary Figure 7d). GFP immunofluorescence imaging in astrocytes confirmed these effects (Figure 4g). Thus, sustained - otherwise physiologiclike - NMDAR signaling in astrocytes promotes p35/Cdk5mediated Nrf2 phosphorylation and nuclear translocation.

Then, we aimed to decipher the transduction pathway leading to p35/Cdk5 activation upon NMDAR signaling in astrocytes. In view that protein kinase $\mathrm{C} \delta(\mathrm{PKC} \delta)$ phosphorylates p35 sustaining its stability, ${ }^{30}$ we used compound U73122 (and its inactive isomer, U73343) ${ }^{31}$ to antagonize PKC $\delta$ upstream step, phospholipase C (PLC), and rottlerin to inhibit PKC $\delta$ directly. ${ }^{32}$ We found that NMDAR-mediated p35 phosphorylation (Figure 4h), and p35 stability (Figure 4i) were decreased by U73122 and by rottlerin (see, also, Supplementary Figure 7e). These results suggest that NMDAR stimulation triggers PLC-dependent PKC $\delta$ activation in astrocytes, leading to p35 phosphorylation that is known to co-activate Cdk5 in the cytosol. In good agreement with this, U73122 (but not U73343), as well as rottlerin, prevented Nrf2 phosphorylation (Figure 4j; Supplementary Figure 7e), and $\left[\mathrm{Ca}^{2+}\right]_{\mathrm{c}}$ increases (Figures $4 \mathrm{k}$ and I) by NMDA. Altogether, these results indicate that NMDAR activation in astrocytes promotes PLC activation through a mechanism that does not require extracellular $\mathrm{Ca}^{2+}$ influx. Active $\mathrm{PLC}$, which triggers a delayed cytosolic $\mathrm{Ca}^{2+}$ rise by promoting its release from the ER, activates PKC $\delta$ that, in turn, phosphorylates p35 to keep Cdk5 active in the cytoplasm to sustain Nrf2 phosphorylation and functional activation.

The NMDAR-Cdk5-Nrf2 pathway in astrocytes sustains antioxidant protection and survival of neurons. To ascertain if our results had physiological significance, we sought to investigate whether NMDAR-mediated enhancement of antioxidant Nrf2 response in astrocytes functionally resulted in neuronal antioxidant protection. Incubation of neurons with $20 \mu \mathrm{M}$ NMDA for $8 \mathrm{~h}$ did not change GSH concentration (Figure 5a), confirming that the stimulation of Nrf2 pathway in neurons is insufficient to improve antioxidant status. However, NMDA $(20 \mu \mathrm{M}, 8 \mathrm{~h})$ did enhance the GSH concentrations in astrocytes (Figure $5 b$ ). Then, we asked whether NMDAR signaling, by stimulating the Cdk5-Nrf2 pathway in astrocytes herein described, would meet the neuronal demands for GSH during neurotransmission. To achieve this, we performed astrocyte-neuronal co-cultures that were incubated in the presence of NMDA $(20 \mu \mathrm{M}, 8 \mathrm{~h})$; after this incubation period, neurons were separated from the astrocytes and analyzed. As shown in Figure 5c, GSH concentration in neurons increased by approximately threefold in coculture with astrocytes; interestingly, NMDA, which in neurons alone did not alter GSH concentrations (Figure 5a), promoted an approximately threefold increase in neuronal GSH concentrations in co-culture with astrocytes (Figure $5 \mathrm{c}$ ). This was a Cdk-dependent effect as the presence of roscovitine in the co-culture prevented NMDAR-mediated increase in neuronal GSH (Figure 5c). Moreover, acivicin, an inhibitor of $\gamma$-glutamyltransferase ${ }^{33}$ that catalyzes the release of GSH precursors from astrocytes, prevented NMDAR-mediated increase in neuronal GSH (Figure 5d). Thus, NMDAR signaling in astrocytes triggers the release of GSH precursors that lead to increased GSH concentrations in neighboring neurons.

Finally, we sought to ascertain whether the astrocyteneuronal supply of GSH precursors influenced neuronal vulnerability against oxidative stress. As shown in Figure 5e, incubation of neurons with $\mathrm{H}_{2} \mathrm{O}_{2}$, after co-cultured with astrocytes, promoted apoptotic neuronal death. However, apoptosis was abolished by the presence of NMDA during coculture, an effect that was rescued by acivicin (Figure 5e). Thus, GSH precursors availability and survival of neurons following astrocyte NMDAR signaling depends on astrocytederived GSH precursors supply to neurons. To assess if neuronal protection by astrocyte NMDAR signaling depends on the Cdk5-Nrf2 transduction pathway, we knocked down Nrf2 (Figures $2 e$ and f) or Cdk5 (Figure 3c) in astrocytes before they were co-cultured with neurons. As shown in

Figure 4 NMDAR activation in astrocytes promotes a phospholipase $\mathrm{C}(\mathrm{PLC})$-protein kinase $\mathrm{C} \delta(\mathrm{PKC} \delta$ )-mediated p35 phosphorylation leading to Cdk5-triggered Nrf2 phosphorylation at residues Thr-395, Ser-433 and Thr-439 and Nrf2 nuclear localization. (a) NMDA (20 $\mu \mathrm{M}, 8 \mathrm{~h}$ ) did not alter the p35 protein levels and did not result in the appearance of p25 in astrocytes. (b) The calpain inhibitor MDL (100 $\mu \mathrm{M})$ did not prevent NMDA (20 $\mu \mathrm{M}, 8 \mathrm{~h})$-mediated increase in Nrf2 phosphorylation in astrocytes. (c) NMDA $(20 \mu \mathrm{M}, 8 \mathrm{~h})$ increased histone $\mathrm{H} 1$ phosphorylation (P-H1) in cytosolic, but not nuclear protein extracts from astrocytes previously immunoprecipitated with an antibody against Cdk5; Gapdh was used as a cytosolic marker, and lamin B was used as a nuclear marker. (d) In vitro Nrf2 phosphorylation assay reveals p35/Cdk5-mediated phosphorylation of wild-type Nrf2 and, at a lower degree, of T395A/S433A/T439A mutant form of Nrf2. (e) Transfection of astrocytes with either wild type (Wt) or T395A/S433A/T439A mutant (Mut) form of Nrf2 fused with GFP, followed by NMDA ( $20 \mu \mathrm{M}, 8 \mathrm{~h})$ treatment, shows that NMDA induces the accumulation of wild type, but not T395A/S433A/T439A mutant Nrf2-GFP. (f) Transfection of astrocytes with either Wt or T395A/S433A/T439A Mut of Nrf2 fused with GFP, followed by NMDA (20 $\mu$ M, $8 \mathrm{~h}$ ) treatment, shows that NMDA induces cytosolic and nuclear accumulation of the wild type, but not of the T395A/S433A/T439A mutant form; a higher exposition time of the film (high exp.) shows Nrf2 in the nucleus; transfection of astrocytes with the phosphomimetic T395D/S433D/T439D Nrf2 mutant (P-mim) shows Nrf2 accumulation in the cytosol and in the nucleus in the absence of NMDA treatment. (g) Transfection of astrocytes with either wild type or T395A/S433A/T439A mutant form of Nrf2 fused with GFP, followed by NMDA (20 $\mu \mathrm{M}, 8 \mathrm{~h})$ treatment and GFP immunofluorescence analysis shows that NMDA induces nuclear accumulation of the wild type, but not of the T395A/S433A/T439A mutant Nrf2 form; transfection of astrocytes with the phosphomimetic T395D/S433D/T439D Nrf2 mutant (Nrf2 P-mim) shows Nrf2 accumulation in the nucleus in the absence of NMDA treatment. Quantification of the proportion of astrocytes with GFP-DAPI co-localization was performed in $~ 150$ cells, and the results are shown. (h) NMDA (20 $\mu \mathrm{M}, 8 \mathrm{~h})$ increases p35 protein phosphorylation in astrocytes, as revealed by anti-phospho-Ser immunoblotting in p35-immunoprecipitated protein extracts; the PLC inactive antagonist, U73433 (10 nM), did not prevent p35 phosphorylation; however, the active PLC antagonist, U73122 (10 nM), prevented p35 phosphorylation; the PKC $\delta$ inhibitor, rottlerin $(25 \mu \mathrm{M})$, either alone or in combination with U73122, abolished the abundance of phospho-p35. (i) PLC inactive antagonist, U73433 (10 nM), did not decrease p35 levels in NMDA (20 $\mu$ M, 8 h)-treated astrocytes; however, the active PLC antagonist, U73122 (10 nM), decreased p35 abundance; and the PKC $\delta$ inhibitor, rottlerin $(25 \mu \mathrm{M})$, either alone or in combination with U73122, induced a loss of p35 protein. (j) The increase in Nrf2 protein phosphorylation, as revealed by anti-phospho-Ser immunoblotting in Nrf2-immunoprecipitated protein extracts of astrocytes treated with NMDA $(20 \mu \mathrm{M}, 8 \mathrm{~h})$, was prevented by U73122 (but not U73433), and by rottlerin, either alone or in combination with U73122. (k) U73343 is unable to alter the NMDA $(20 \mu \mathrm{M})$-mediated increase in $\left[\mathrm{Ca}^{2+}\right]_{\mathrm{c}}$ in individual astrocytes. (I) U73122 largely prevented NMDA (20 $\left.\mu \mathrm{M}\right)$-induced increase in $\left[\mathrm{Ca}^{2+}\right]_{\mathrm{c}}$. Data are expressed as mean $\pm \mathrm{S}$.E.M. ${ }^{*} P<0.05$ (ANOVA followed by Bonferroni test; $n=3-4$ independent experiments) 
a

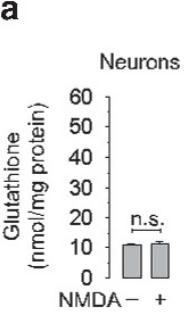

b

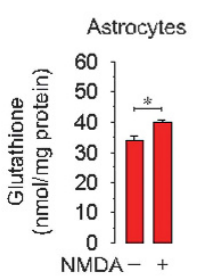
Neurons co-cultured with astrocytes

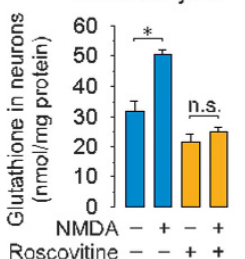

d Neurons co-cultured with astrocytes

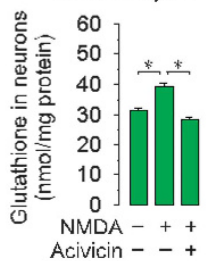

e

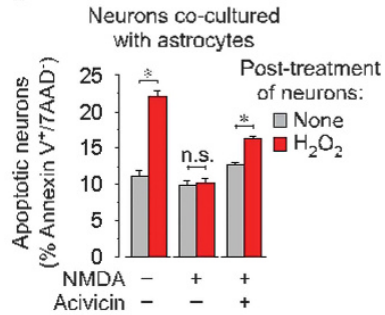

f

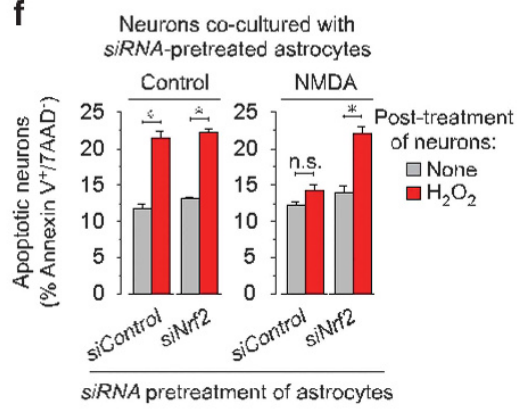

g

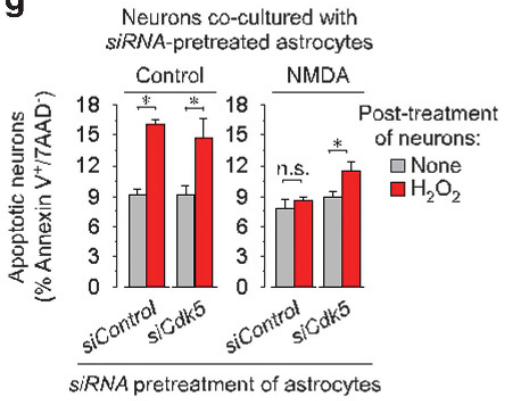

h

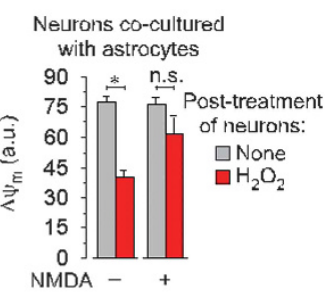

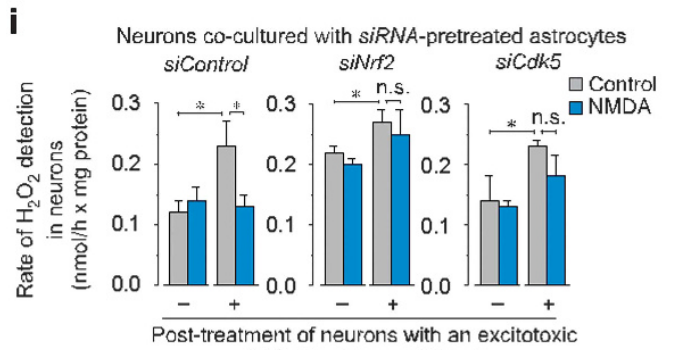

$(100 \mu \mathrm{M}$ glutamate) insult

Figure 5 NMDA-mediated activation of the Cdk5-Nrf2 pathway in astrocytes sustains the antioxidant protection and survival of co-cultured neurons. (a) NMDA (20 $\mu \mathrm{M}, 8 \mathrm{~h}$ ) did not change GSH concentration in neurons. (b) NMDA $(20 \mu \mathrm{M}, 8 \mathrm{~h})$ increased GSH concentration in astrocytes. (c) Incubation of neurons with astrocytes in co-culture for $8 \mathrm{~h}$ increased GSH concentrations in neurons by approximately threefold when compared with neurons cultured alone (a); incubation of the astrocyte-neuronal co-culture with NMDA $(20 \mu \mathrm{M}, 8 \mathrm{~h})$ increased, by 1.7-fold, GSH concentration in neurons, an effect that prevented by roscovitine $(10 \mu \mathrm{M})$. (d) Incubation of the astrocyte-neuronal co-culture with acivicin $(100 \mu \mathrm{M})$ prevented NMDA (20 $\mu \mathrm{M}, 8 \mathrm{~h})$-mediated increase in neuronal GSH concentration. (e) Incubation of neurons, after the $8 \mathrm{~h}$ co-incubation period with astrocytes, with $\mathrm{H}_{2} \mathrm{O}_{2}(400 \mu \mathrm{M})$ increased neuronal apoptotic death, determined after $1 \mathrm{~h}$; the presence of NMDA $(20 \mu \mathrm{M})$ during co-incubation yielded neurons resistant to the $\mathrm{H}_{2} \mathrm{O}_{2}$ insult; however, this resistance was lost by acivicin. (f) Incubation of neurons, after the $8 \mathrm{~h}$ co-incubation period with astrocytes, with $\mathrm{H}_{2} \mathrm{O}_{2}(400 \mu \mathrm{M})$ increased neuronal apoptotic death (after $1 \mathrm{~h}$ ) if astrocytes in co-culture were transfected with a siControl, but the presence of NMDA $(20 \mu \mathrm{M})$ during the co-culture prevented this effect; however, Nrf2 knockdown (siNrf2) in astrocytes before the co-culture was unable to prevent $\mathrm{H}_{2} \mathrm{O}_{2}$-induced neuronal apoptotic death, regardless the presence of NMDA during co-culture. (g) Incubation of neurons, after the $8 \mathrm{~h}$ co-incubation period with astrocytes, with $\mathrm{H}_{2} \mathrm{O}_{2}(400 \mu \mathrm{M})$ increased neuronal apoptotic death (after $\left.1 \mathrm{~h}\right)$ if astrocytes in co-culture were transfected with a siControl, but the presence of NMDA $(20 \mu \mathrm{M})$ during the co-culture prevented this effect; however, Cdk5 knockdown (siCdk5) in astrocytes before the co-culture was unable to prevent $\mathrm{H}_{2} \mathrm{O}_{2}$-induced neuronal apoptotic death, regardless of the presence of NMDA during co-culture. (h) Incubation of neurons, after the 8-h co-incubation period with astrocytes, with $\mathrm{H}_{2} \mathrm{O}_{2}(400 \mu \mathrm{M})$ decreased neuronal mitochondrial inner membrane potential $\left(\Delta \psi_{\mathrm{m}}\right)$, determined after $1 \mathrm{~h}$, an effect that was abolished if NMDA (20 $\left.\mu \mathrm{M}\right)$ was present during the astrocyte-neuronal co-culture incubation period. (i) After $8 \mathrm{~h}$ of neuronal co-culture with astrocytes (either in the absence or in the presence of NMDA $20 \mu \mathrm{M}$ ), astrocytes were removed, and neurons alone were further incubated (or not) with glutamate ( $100 \mu \mathrm{M} / 15 \mathrm{~min}$, followed by $1 \mathrm{~h}$ in DMEM; post treatment with an excitotoxic insult); this excitotoxic insult increased $\mathrm{H}_{2} \mathrm{O}_{2}$, an effect that was prevented if NMDA was present during the co-culture period; however, NMDA was unable to prevent excitotoxic-induced $\mathrm{H}_{2} \mathrm{O}_{2}$ increase if Nrf2 or $\mathrm{Cdk} 5$ were knocked down (siNrf2 or siCdk5) in astrocytes before the co-culture. Data are expressed as mean \pm S.E.M. ${ }^{*} P<0.05$ (Student's t-test for a-c, e-h; ANOVA followed by Bonferroni test for $\mathbf{d}$ and $\mathbf{i} ; n=3-4$ independent experiments)

Figures $5 f$ and g, Nrf2 or Cdk5 knockdown, respectively, in astrocytes abolished the neuroprotective effect of NMDAR signaling. Moreover, a decrease in neuronal $\Delta \psi_{\mathrm{m}}$ was observed by $\mathrm{H}_{2} \mathrm{O}_{2}$, but this was abolished by NMDA during the co-culture (Figure 5h). Finally, the increased $\mathrm{H}_{2} \mathrm{O}_{2}$ formation triggered by an excitotoxic insult (glutamate $100 \mu \mathrm{M} / 15 \mathrm{~min}$ ) to neurons was prevented by NMDA in the astrocyte-neuronal co-culture (Figure 5i). However, the knockdown of Nrf2 or Cdk5 in astrocytes, before co-cultured with neurons, were unable to rescue NMDA-mediated protection against excitotoxic-induced neuronal $\mathrm{H}_{2} \mathrm{O}_{2}$ formation (Figure 5i). Thus, the Cdk5-Nrf2 transduction pathway in astrocytes during NMDAR signaling sustains antioxidant protection and survival of neurons.

\section{Discussion}

During neurotransmission, neurons unavoidably trigger ROS production, but their weak antioxidant defense does not meet protection. Here we show that NMDAR activity in astrocytes 
exerts neuronal antioxidant protection, and we provide a signaling pathway for this effect (Supplementary Figure 8). Thus, astrocytes, by sensing glutamatergic neurotransmission through their NMDAR, sustain a PLC-PKC $\delta$-mediated p35/ Cdk5-Nrf2 transduction pathway that allows neurons to receive GSH precursors for the endogenous de novo biosynthesis. We also show that, though weakly, the Nrf2 system occurs in neurons where it is amenable by NMDARdependent upregulation; however, it is insufficient to provide self-protection, even if astrocytes are present. Thus, our results may explain the enigma of the very weak antioxidant capacity of neurons. ${ }^{34}$

We also observe that the release of $\mathrm{Ca}^{2+}$ from the $\mathrm{ER}$ participates in Nrf2 phosphorylation upon NMDAR activation in astrocytes. However, as PKC $\delta$ is $\mathrm{Ca}^{2+}$ insensitive, ${ }^{35}$ but amenable to activation by diacylglycerol ${ }^{35}$ - the PLC activity product - we propose that PKC $\delta$ is activated by DAG upon NMDAR activation. Therefore, our data strongly suggest that NMDAR, at least in astrocytes, transduce a metabotropic-like signal. However, understanding the specific mechanism of its occurrence remains to be elucidated. The specific function played by ER-released $\mathrm{Ca}^{2+}$ in the signaling cascade leading to Nrf2 phosphorylation also remains apparently obscure. However, it should be mentioned that, at least in neurons, ERreleased $\mathrm{Ca}^{2+}$ exerts a positive feedback activation loop on PLC. ${ }^{36}$ Provided this phenomenon also occurs in astrocytes upon NMDAR activation, we hypothesize that it would allow sustaining a positive loop of PLC-mediated PKC $\delta$ activation, thus keeping Nrf2 continuously active during long periods of neurotransmission. Moreover, Nrf2 is known to be phosphorylated at $\mathrm{S} 40$ by $\mathrm{PKC} \delta,{ }^{37}$ although this is necessary, but not sufficient, to promote Nrf2 nuclear translocation. Our data therefore support a critical role for $\mathrm{PKC} \delta$ in astrocyte Nrf2mediated antioxidant response, as it would coordinate a permissive Nrf2-S40 phosphorylation, with an active p35/ Cdk5-mediated Nrf2-T395/S433/T439 phosphorylation. Whether this Cdk5-Nrf2 transduction pathway accounts for neuroprotection during ischemic preconditioning ${ }^{18}$ is a tempting possibility yet to be determined. However, the fact that ischemic preconditioning may be dependent on astrocyte Nrf2 transcriptional activity ${ }^{18}$ strongly supports this notion.

Our results also support the notion that astrocytes are active players in neurotransmission. Thus, astrocytes are critical for neuronal function by actively modulating neuronal receptors. ${ }^{38}$ However, upon neuronal activity, astrocytes can supply metabolic substrates, such as lactate, which neurons can use for energy provision ${ }^{39,40}$ as well as for modulating neurotransmission. ${ }^{41}$ Here we now decipher a molecular mechanism that explains the link between neuronal synaptic activity with astrocyte provision of antioxidant precursors to sustain neuronal survival. Whether this NMDAR-p35/Cdk5 pathway would also account for lactate provision from astrocytes to neurons ${ }^{39,40}$ remains a tempting possibility yet to be explored. Furthermore, the involvement of Cdk5 as a key player in this process suggests additional function(s) for this antioxidant pathway. Thus, Cdk5-Nrf2 signaling seems to be ubiquitous, in view of its occurrence in neurons besides astrocytes. Nrf2 is also elevated in cancer cells, ${ }^{13,42,43}$ hence it is tempting to speculate that Cdk5 - which contributes to cancer progression ${ }^{44}$ - would sustain Nrf2-mediated antioxidant activity and survival of rapidly proliferating cells.

\section{Materials and Methods}

Ethical use of animals. Rats were bred at the Animal Experimentation Unit of the University of Salamanca, and all protocols were approved by the Bioethics Committee of the University of Salamanca in accordance with the Spanish legislation (RD53/2013)

Cell cultures and co-cultures. Primary cultures of rat cortical neurons were prepared from fetal Wistar rats of 16 days of gestation, ${ }^{45}$ seeded at $2.5 \times 10^{5}$ cells/ $\mathrm{cm}^{2}$ in different size plastic plates coated with poly-D-lysine $(15 \mu \mathrm{g} / \mathrm{ml})$ and incubated in DMEM (Sigma, Madrid, Spain) supplemented with 10\% fetal calf serum (FCS; Roche Diagnostics, Heidelberg, Germany). Cells were incubated at $37^{\circ} \mathrm{C}$ in a humidified $5 \% \mathrm{CO}_{2}$-containing atmosphere. At $48 \mathrm{~h}$ after plating, the medium was replaced with DMEM supplemented with $5 \%$ horse serum (Sigma), $20 \mathrm{mM}$ D-glucose and, on day 4 , cytosine arabinoside $(10 \mu \mathrm{M})$ to prevent non-neuronal proliferation. Cells were used for the experiments on day 6 in vitro (DIV). Rat cortical astrocytes in primary culture were obtained from 0 to 24-h-old neonates, and cell suspension seeded at $2.5 \times 10^{5} \mathrm{cells} / \mathrm{cm}^{2}$ in DMEM supplemented with $10 \%$ FCS in $175 \mathrm{~cm}^{2}$ plastic flasks. To detach non-astrocytic cells, after 1 week in vitro, the flasks were shaken at 200 r.p.m. overnight, the supernatant discarded and the attached, astrocyte-enriched cells, were reseeded in different size plates. To obtain astrocyteneuronal co-culture, astrocytes were reseeded on $10 \mathrm{~cm}^{2}$ inserts $(0.4 \mu \mathrm{m}$ pore size, Millipore Merck, Darmstadt, Germany) and allowed to attach for $24 \mathrm{~h}$. After this time, astrocytes were treated, or not, before the inserts were co-cultured with 6 DIV neurons. Human embryonic kidney-293 T (HEK293T) cells were maintained in DMEM supplemented with 10\% (v/v) FCS. Twenty-four hours before the experiment, the cells were reseeded at $1.8 \times 10^{5} \mathrm{cells} / \mathrm{cm}^{2}$ in plates previously coated with polyD-lysine $(15 \mu \mathrm{g} / \mathrm{ml})$.

Plasmids constructions and site-directed mutagenesis. Human Nrf2 full-length cDNA (1,817 pb, accession number, NM_006164.3; plasmid pT-RExDEST30) was purchased from Source Bioscience (Nottingham, U.K.) and subcloned in PEGFP-C1 vector (Invitrogen) in phase with the full-length CDNA encoding the green fluorescent protein (GFP) at Nrf2 5 '-terminus using the forward and reverse oligonucleotides, respectively, 5'-CGGGATCCGCGATGATGGACTTG GAGCTGCCGCCGCCGGGA-3' and 5'-CGGGATCCGCGCTAGTTTTTCTTAACA TCTGGCTTCTTACT-3' (BamHI sites underlined), which were purchased from Thermo Scientific (Offenbach, Germany), and then sequence verified. This GFPNrf2 cDNA fusion construct was then subjected to site-directed mutagenesis on T395, S433 and T439, which were replaced by Ala or Asp residues to obtain the phosphodefective (Nrf2-A) and phosphomimetic (Nrf2-D) forms or Nrf2, respectively, using QuikChange XL kit (Stratagene, La Jolla, CA, USA), followed by Dpnl digestion. The forward and reverse oligonucleotides designed for this mutation were, respectively, 5'-AACAGAATGGTCCTAAAGCACCAGTACATTCTTCTG-3' and 5'-CAGA AGAATGTACTGGTGCTTTAGGACCATTCTGTT-3' for T395A; 5'-ATTGCCTGTAGC TCCTGGTCATCGGAAAGCCCCATTCAC-3' and 5'-GTGAATGGGGCTTTCCGAT GACCAGGAGCTACAGGCAAT-3' for S433A/T439A; 5'-ACAGAATGGTCCTAAA GATCCAGTACATTCTTCTGG-3' and 5'-CCAGAAGAATGTACTGGATCTTTAGGAC CATTCTGT-3' for T395D; 5'-GAGAAAGAATTGCCTGTAGATCCTGGTCATCGGAA AACCC-3' and 5'-GGGTTTTCCGATGACCAGGATCTACAGGCAATTCTTTCTC-3' for S433D; and 5'-ATCCTGGTCATCGGAAAGACCCATTCACAAAAGA-3' and 5'-TCTTTTGTGAATGGGTCTTTCCGATGACCAGGAT-3' for T439D. For Nrf2 protein purification, the Nrf2 cDNA was fused, on its $5^{\prime}$-terminus, with the fulllength cDNA encoding glutathione-S-transferase (GST) in pGEX-2 $T$ vector (GE Healthcare Life Science, Barcelona, Spain), expressed in Bcl2 bacteria strain, and purified using GSH-sepharose beads.

Small interference RNA. To obtaine specific protein knockdown, we used the following small interference RNA (siRNAs; only the forward strand shown), nuclear factor (erythroid-derived 2)-like 2 (Nrf2), 5'-CUGUUGAUGACUUCAAUGA-3' (nucleotides 1473-1492 for rat NM_031789); cullin3 (Cul3), 5'-UGACAGA AAACACGAGAUA-3' (nucleotides 2031-2050 for rat NM_001106923); cyclindependent kinase-5 (Cdk5), 5'-AAGCCGUACCCGAUGUAUC-3' (nucleotides 859 - 877 for rat NM_080885). ${ }^{46}$ In all cases, an siRNA against luciferase (5'-CUGACGCGGAAUACUUCGAUU-3') was used as control siRNA (siControl). ${ }^{47}$ 
Annealed siRNAs were purchased from Dharmacon (Abgene, Thermo Fisher, Epsom, UK).

Cell treatments. All transfections with plasmids of primary cultures were performed using either Lipofectamine 2000 or Lipofectamine LTX+Reagent Plus (Invitrogen, Madrid, Spain), following the manufacturer's instructions. Astrocytes and neurons were transfected with $0.16-1.6 \mathrm{~g} / \mathrm{ml}$ of the plasmid vectors at 12-14 DIV or 5 DIV, respectively, and used on the following day. HEK293T we transfected using $1 \mu \mathrm{M}$ polyethylenimine (PEI, Sigma). Transfections of astrocytes or neurons with siRNAs were performed using Lipofectamine RNAiMAX (Invitrogen) following the manufacturer's instructions and used after $72 \mathrm{~h}$. According to the degree of protein knockdown consistently observed by this procedure, the efficiency of transfection of siRNAs is estimated to be $80-90 \%$. To activate NMDA receptors, cells were incubated with different concentrations of NMDA (1-100 $\mu \mathrm{M}$; Sigma catalog number M3262) for 8-24h in DMEM without FCS. Where indicated, incubations were performed in the presence of MK801 (10 $\mu \mathrm{M}$; Sigma), roscovitine (10 $\mu \mathrm{M}$; Sigma), MDL ( $100 \mu \mathrm{M}$; Calbiochem, Darmstadt, Germany), rottlerin $(25 \mu \mathrm{M}$; Santa Cruz Biotechnologies, Heidelberg, Germany), U73122 (10 nM; Millipore), U73343 (10 nM; Millipore), acivicin $(100 \mu \mathrm{M}$; Santa Cruz Biotechnologies), EGTA (100 $\mu \mathrm{M}$ in $\mathrm{Ca}^{2+}$-free DMEM; Sigma), BAPTA $(10 \mu \mathrm{M}$; Calbiochem), tert-butylhydroquinone

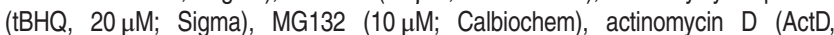
$100 \mathrm{ng} / \mathrm{ml}$; Sigma) or $\mathrm{H}_{2} \mathrm{O}_{2}(400 \mu \mathrm{M})$. To promote an excitotoxic insult, neurons were incubated with $100 \mu \mathrm{M}$ glutamate plus $10 \mu \mathrm{M}$ glycine in buffered Hank's solution $\left(134.2 \mathrm{mM} \mathrm{NaCl}, 5.26 \mathrm{mM} \mathrm{KCl}, 0.43 \mathrm{mM} \mathrm{KH}_{2} \mathrm{PO}_{4}, 4.09 \mathrm{mM} \mathrm{NaHCO} 3,0.33 \mathrm{mM}\right.$ $\mathrm{Na}_{2} \mathrm{HPO}_{4}, 5.44 \mathrm{mM}$ glucose, $20 \mathrm{mM}$ HEPES, $\left.4 \mathrm{mM} \mathrm{CaCl}_{2}, \mathrm{pH} 7.4\right)^{48}$; after $15 \mathrm{~min}$, the buffer was removed and cells further incubated for $1-4 \mathrm{~h}$ in DMEM without FCS.

Subcellular fractionation. To fractionate cytosol from nucleus, cells were washed with cold phosphate-buffered saline (PBS) containing $1 \mathrm{mM} \mathrm{MgCl}$, harvested with cytosolic buffer (10 mM HEPES, $1.5 \mathrm{mM} \mathrm{MgCl} 2,10 \mathrm{mM} \mathrm{KCl}, 1 \mathrm{mM}$ EDTA, NP-40 0.1\%, v/v, $1.5 \mathrm{M}$ sucrose and protease and phosphatase inhibitors cocktail, pH 7.9), triturated with a micropipette to promote cell lysis, left on ice for $30 \mathrm{~min}$ and vortexed for $10 \mathrm{~s}$. After checking cell lysis under a light microscope, extracts were centrifuged at $830 \times \mathrm{g}$ for $10 \mathrm{~min}$ and the cytosolic fraction (supernatant) was removed and boiled for $5 \mathrm{~min}$. Lysis of the nuclei was performed by resuspending the nuclear pellet in nuclear buffer $\left(50 \mathrm{mM} \mathrm{HEPES}, 1.5 \mathrm{mM} \mathrm{MgCl}_{2}\right.$, $10 \mathrm{mM} \mathrm{KClmM}, 0.5 \mathrm{mM} \mathrm{NaCl}, 1 \mathrm{mM}$ EDTA, NP-40 1\%, v/v, and protease and phosphatase inhibitor cocktail, $\mathrm{pH} 7.9$ ), triturated with a micropipette, left on ice for $2 \mathrm{~h}$, vortexed (10 s), boiled (5 $\mathrm{min})$ and sonicated (5 $\mathrm{min})$.

Western blotting. Cells or subcellular fractions were lysed in RIPA buffer ( $2 \%$ sodium dodecylsulphate, $2 \mathrm{mM}$ EDTA, $2 \mathrm{mM}$ EGTA and $50 \mathrm{mM}$ Tris $\mathrm{pH} 7.5$ ), supplemented with phosphatase inhibitors $(100 \mu \mathrm{M}$ phenylmethylsulfonyl fluoride, $50 \mu \mathrm{g} / \mathrm{ml}$ antipapain, $50 \mu \mathrm{g} / \mathrm{ml}$ pepstatin, $50 \mu \mathrm{g} / \mathrm{ml}$ amastatin, $50 \mu \mathrm{g} / \mathrm{ml}$ leupeptin, $50 \mu \mathrm{g} / \mathrm{ml}$ bestatin, $1 \mathrm{mM}$ o-vanadate, $50 \mathrm{mM} \mathrm{NaF}$ and $50 \mu \mathrm{g} / \mathrm{ml}$ soybean trypsin inhibitor) and boiled for $5 \mathrm{~min}$. Extracts were centrifuged at $13,000 \mathrm{xg}$ for $5 \mathrm{~min}$ at $4{ }^{\circ} \mathrm{C}$, and aliquots of lysates ( $50 \mu \mathrm{g}$ protein, unless otherwise stated) were subjected to SDS-polyacrylamide (SDS-PAGE) electrophoresis on a 8, 10 or $12 \%$ acrylamide gel (MiniProtean, Bio-Rad, Hercules, CA, USA) including BenchMark (Invitrogen) or Dual Colors (Bio-Rad) as prestained protein ladders. The resolved proteins were transferred electrophoretically to nitrocellulose membranes (Hybond-ECL, Amersham Bioscience Europe, Barcelona, Spain). Membranes were blocked with $5 \%$ (w/v) low-fat milk in $20 \mathrm{mM}$ Tris, $500 \mathrm{mM} \mathrm{NaCl}$ and $0.1 \%$ (w/v) Tween 20, pH 7.5, for $1 \mathrm{~h}$. After blocking, the membranes were immunoblotted with primary antibodies at dilutions ranging from 1:200 to 1:1000 overnight at $4^{\circ} \mathrm{C}$. After incubation with horseradish peroxidase-conjugated goat anti-rabbit IgG (Santa Cruz Biotechnologies), goat anti-mouse IgG (Santa Cruz Biotechnologies), or rabbit anti-goat IgG (Santa Cruz Biotechnologies; all at 1:10,000 dilution), membranes were immediately incubated with the enhanced chemiluminescence kit SuperSignal West Dura (Pierce, Thermo Scientific, Rockford, IL, USA) for $5 \mathrm{~min}$ or Immobilon Western Chemiluminiscent HRP Substrate (Merck Millipore) for $1 \mathrm{~min}$, before exposure to Kodak XAR-5 film for 1-5 min, and the autoradiograms scanned. Biologically independent replicates (two to four) were always performed, and a representative western blot is shown. The protein abundances were measured by densitometry of the bands on the films using ImageJ 1.48 u4 software (National Institutes of Health, USA), and were normalized against the corresponding loading control.

Primary antibodies for western blotting. Immunoblotting was performed using mouse monoclonal anti-Gapdh (AM4300, Ambion, Austin, TX, USA), mouse monoclonal anti- $\beta$-actin (A3854, Sigma), rabbit polyclonal anti- $\beta$ III-tubulin (ab18207, Abcam), rabbit polyclonal anti-Nup98 (2292, Cell Signaling, Boston, MA, USA), mouse monoclonal anti-lamin B (sc374015, Santa Cruz Biotechnologies), mouse monoclonal anti-Map2 (M2320, Sigma), rabbit polyclonal anti-Gfap (G9269, Sigma), goat polyclonal anti-Nrf2 (sc30915, Santa Cruz Biotechnologies), mouse monoclonal anti-Keap1 (60027-1-lg, ProteinTech), rabbit monoclonal anti-Cul3 (ab75851, Abcam), rabbit polyclonal anti-Cdk5 (sc-173, Santa Cruz Biotechnologies), rabbit polyclonal anti-p35 (sc-820, Santa Cruz Biotechnologies), rabbit polyclonal anti-phosphoserine (61-8100, Invitrogen), rabbit polyclonal anti-GFP (ab6556, Abcam), $\beta 5$-integrin (14-0497, eBioscience), anti-Nr2a and anti-Nr2b (generously donated by A. Fernandez-Lopez, University of Leon, Spain). ${ }^{49}$

Immunoprecipitation assay. For immunoprecipitation of endogenous proteins, neurons and astrocytes were lysed in RIPA buffer supplemented with the phosphatase and protease inhibitor cocktail indicated above. Cell extracts were clarified by centrifugation, and the supernatants (100-200 $\mu \mathrm{g}$ protein) were incubated with anti-Nrf2 $(1 \mu \mathrm{g})$, anti-Cdk5 $(2 \mu \mathrm{g})$ or anti-p35 $(1 \mu \mathrm{g})$ for $4 \mathrm{~h}$ at $4^{\circ} \mathrm{C}$, followed by the addition of $30 \mu \mathrm{l}$ of protein A-agarose (GE Healthcare Life Sciences, Uppsala, Sweden) for $2 \mathrm{~h}$ at $4^{\circ} \mathrm{C}$. Inmunoprecipitates were extensively washed with lysis buffer and detected by western blot analysis.

Determination of $\mathrm{H}_{2} \mathrm{O}_{2}$. For $\mathrm{H}_{2} \mathrm{O}_{2}$ assessments, $1.8 \times 10^{4}$ suspended cells were incubated in $50 \mu \mathrm{M}$ of AmplexRed reagent (Invitrogen) in Krebs-Ringer phosphate buffer ( $145 \mathrm{mM} \mathrm{NaCl}, 5.7 \mathrm{mM} \mathrm{Na}_{2} \mathrm{PO}_{4}, 4.86 \mathrm{mM} \mathrm{KCl}, 0.54 \mathrm{mM} \mathrm{CaCl}$, $1.22 \mathrm{mM} \mathrm{MgSO}_{4}$ and $5.5 \mathrm{mM}$ glucose, $\mathrm{pH} 7.4$ ), containing horseradish peroxidase $(0.1 \mathrm{U} / \mathrm{ml})$. The luminescence was recorded for $2 \mathrm{~h}$ at $30 \mathrm{~min}$ intervals using a Fluoroskan Ascent FL (Thermo Scientific) fluorimeter (excitation: $538 \mathrm{~nm}$, emission: $604 \mathrm{~nm}$ ), and the slopes were used for calculations.

Mitochondrial membrane potential. The mitochondrial membrane potential $\left(\Delta \psi_{\mathrm{m}}\right)$ was assessed using the MitoProbe DilC $_{1}\left(1,1^{\prime}, 3,3,3^{\prime}, 3^{\prime}\right.$ hexamethylindodicarbo-cyanine iodide, $10 \mu \mathrm{M}$ ) Assay Kit for flow cytometry (Life Technologies, Eugene, OR, USA). For this purpose, cells were incubated with the dye at $37^{\circ} \mathrm{C}$ for $15 \mathrm{~min} . \Delta \psi_{\mathrm{m}}$ values were expressed in arbitrary units (a.u.), using carbonyl cyanide 4-(trifluoromethoxy) phenylhydrazone (CCCP; $50 \mu \mathrm{M}$ ) for $15 \mathrm{~min}$ to define the $0 \Delta \psi_{\mathrm{m}}$ value.

Cytosolic $\mathrm{Ca}^{2+}$ determination using Fura-2 fluorescence. To monitor intracellular free $\mathrm{Ca}^{2+}$ concentrations $\left(\left[\mathrm{Ca}^{2+}\right]_{c}\right)$ astrocytes growing on coverslips were incubated with Fura-2/AM $(4 \mu \mathrm{M})$ at $23-25^{\circ} \mathrm{C}$ for 40 min in a $\mathrm{Na}^{+}$Hepes buffer containing (in mM), $140 \mathrm{NaCl}, 4.7 \mathrm{KCl}, 1.3 \mathrm{CaCl}_{2}, 2 \mathrm{MgCl}_{2}, 10 \mathrm{mM}$ Hepes, $10 \mathrm{mM}$ glucose and $0.2 \%$ (w/v) bovine serum albumin $(\mathrm{pH}, 7.4) .{ }^{50}$ After the extracellular medium was discarded, it was replaced with fresh $\mathrm{Na}^{+}$-HEPES buffer without Fura-2/AM and cells were immediately used. Coverslip-containing cells were mounted on an experimental perfusion chamber and placed on the stage of an epifluorescence inverted microscope (Nikon Diaphot T200, Melville, NY, USA). For fura-2 fluorescence changes determination, an image acquisition and analysis system for video microscopy was employed (Hamamatsu Photonics, Hamamatsu, Japan). Cells were alternatively excited at $340 / 380 \mathrm{~nm}$ with light from a xenon arc lamp passed through a high-speed monochromator (Polychrome IV, Photonics, Hamamatsu, Japan). Fluorescence emission at $505 \mathrm{~nm}$ was detected using a cooled digital CCD camera (Hisca CCD C-6790, Hamamatsu, Japan) and recorded using dedicated software (Aquacosmos 2.5, Hamamatsu Photonics). Under these conditions, Fura-2-emitted fluorescence closely reflects changes in $\left[\mathrm{Ca}^{2+}\right]_{c},{ }^{51}$ and the results are expressed as the ratio of fluorescence emitted at both excitation wavelengths (previously normalized to the resting fluorescence). Stimuli were dissolved in the extracellular Na-HEPES buffer and applied directly to the cells in the perfusion chamber. In the experiments where $\mathrm{Ca}^{2+}$ free medium was employed, $\mathrm{Ca}^{2+}$ was omitted from the extracellular solution and $500 \mu \mathrm{M}$ EGTA was added to the medium. Intracellular-free $\mathrm{Ca}^{2+}$ concentrations in neurons were estimated by recording the Fura-2-emitted fluorescence using a Varioskan Flash (Thermo Fischer, Vantaa, Finland) spectrofluorometer in cells seeded in 96-wells plates. Biologically independent replicates (two to five replicas of 40-60 cells each) were performed, but a representative record is shown. In some experiments, $\left[\mathrm{Ca}^{2+}\right]_{\mathrm{c}}$ were determined in pooled astrocytes in suspension loaded with fura-2-AM $(4 \mu \mathrm{M})$ at room temperature $\left(23-25^{\circ} \mathrm{C}\right)$ for $40 \mathrm{~min}$. Changes in fluorescence signals were monitored by placing aliquots of dye-loaded cells into a cuvette in a fluorescence spectrofluorimeter (RF-5001-PC; Shimadzu, Kyoto, Japan) with continuous stirring at $37^{\circ} \mathrm{C}$. Cells were then excited alternatively at 340 and $380 \mathrm{~nm}$, and fluorescence 
emission was measured at $505 \mathrm{~nm}$. Results are expressed as absolute increases of the ratio of fluorescence above the basal (resting) fluorescence (previously normalized to the resting fluorescence) after the addition of the stimulus, and are shown as the mean \pm S.E.M.

Determination of GSH concentrations. Cells were lysed with $1 \%(\mathrm{w} / \mathrm{v})$ of sulfosalicylic acid, centrifuged at $13,000 \mathrm{xg}$ for $5 \mathrm{~min}$ at $4{ }^{\circ} \mathrm{C}$, and the supernatants were used for the determination of total GSH (i.e., reduced GSH concentration plus twice the concentration of oxidized GSH), using GSSG $(0-50 \mu \mathrm{M})$ as standard as described previously. ${ }^{52}$ Total GSH was measured in reaction buffer $(0.1 \mathrm{mM}$ $\mathrm{NaHPO}_{4}, 1 \mathrm{mM}$ EDTA, $0.3 \mathrm{mM}$ DTNB, $0.4 \mathrm{mM}$ NADPH, GSH reductase $1 \mathrm{U} / \mathrm{ml}$, pH 7.5) by recording the increase in the absorbance after the reaction of reduced GSH with DTNB for 2.5 min at $15 \mathrm{~s}$ intervals using a Multiskan Ascent (Thermo Electron Corp, Basingstoke, United Kingdom) spectrophotometer (excitation: $405 \mathrm{~nm}$ ).

Flow cytometric analysis of apoptotic cell death. Cells were carefully detached from the plates using $1 \mathrm{mM}$ EDTA (tetrasodium salt) in PBS (pH 7.4). APC-conjugated annexin-V and 7-amino-actinomycin D (7-AAD) (Becton Dickinson Biosciences, Bergen, NJ, USA) were used to determine quantitatively the percentage of apoptotic neurons by flow cytometry. Cells were stained with annexin-V-APC and 7-AAD in binding buffer (100 mM HEPES, $140 \mathrm{mM} \mathrm{NaCl}$, $2.5 \mathrm{mM} \mathrm{CaCl}_{2}$ ), according to the manufacturer's instructions, and $5 \times 10^{4}$ cells were analyzed, in three replicates per condition, on a FACScalibur flow cytometer $(15 \mathrm{~mW}$ argon ion laser tuned at $488 \mathrm{~nm}$; CellQuest software, Becton Dickinson Biosciences). Annexin ${ }^{+}$and 7-AAD ${ }^{-}$cells were considered apoptotic. The analyzer threshold was adjusted on the flow cytometer channel to exclude most of the subcellular debris in order to reduce the background noise owing to the neurite disruption during neuronal detaching. Data were expressed as percentages.

Flow cytometric detection of Map2 and Gfap. To characterize primary neuronal cultures, cells were fixed and permeabilized using the Fix\&Perm kit (BD) and incubated with anti-Map2 (neuronal marker) and Gfap (glial marker) antibodies at $4{ }^{\circ} \mathrm{C}$ overnight. On the next day, the cells were incubated with the secondary Cy2 and Cy3-conjugated antibodies, respectively, for $1 \mathrm{~h}$ at room temperature and analyzed in the cytometer using FL1 and FL3 channels, respectively.

Cell sorting. Cortical neurons in primary culture were carefully detached with tetrasodium EDTA $1 \mathrm{mM}$ in PBS (pH 7.4) and incubated with an anti-integrin $\beta 5$ (a plasma membrane specific astrocyte marker) ${ }^{53}$ antibody at $4{ }^{\circ} \mathrm{C}$ overnight. On the next day, cells were incubated with the secondary Alexa 488-conjugated IgG mouse antibody for $1 \mathrm{~h}$ at room temperature, and then resuspended in $500 \mu \mathrm{l}$ of PBS for analysis using a FACSAria III cell sorter (BD Biosciences). Integrin- $\beta 5^{+}$and integrin$\beta 5^{-}$cells were collected in different tubes and lysed with RIPA buffer for western blot analysis.

In vitro p35/Cdk5 kinase assay. Neurons were lysed in ice-cold buffer containing $50 \mathrm{mM}$ Tris- $\mathrm{HCl}$ (pH 7.5), $150 \mathrm{mM} \mathrm{NaCl}, 10 \mathrm{mM}$ EDTA, 2 mM EGTA, 1\% NP-40, supplemented with the phosphatase and protease inhibitor cocktail cited above. After clearing debris by centrifugation, extracts (500 $\mu \mathrm{g}$ protein) were incubated with anti-Cdk5 $(2 \mu \mathrm{g})$ for $4 \mathrm{~h}$ at $4^{\circ} \mathrm{C}$, followed by the addition of $30 \mu \mathrm{l}$ of protein A-sepharose (GE Healthcare Life Sciences, Uppsala, Sweden), for $2 \mathrm{~h}$ at $4^{\circ} \mathrm{C}$. Immunoprecipitates were washed for four times in lysis buffer and resuspended in kinase buffer $\left(20 \mathrm{mM}\right.$ Tris- $\mathrm{HCl} \mathrm{pH} \mathrm{7.6,20} \mathrm{mM} \mathrm{MgCl}, 2 \mathrm{mM} \mathrm{MnCl}_{2}$, $1 \mathrm{mM}$ EDTA, $1 \mathrm{mM}$ EGTA, $0.1 \mathrm{mM}$ dithiothreitol) containing $50 \mu \mathrm{M}$ ATP, $2 \mu \mathrm{Ci}$ of $\left[\gamma_{-}{ }^{32}\right.$ P]ATP and histone $\mathrm{H} 1$ ( $1 \mathrm{mg} / \mathrm{ml}$; Sigma). Samples were subjected to SDSpolyacrylamide gel $(12 \%)$ electrophoresis and transferred proteins were visualized by autoradiography or blotted with anti-Cdk5. ${ }^{54}$ GST-Nrf2 wild type and GST-Nrf2 mutant (phosphodefective) were expressed in $10 \mathrm{ml}$ of Bl21 culture medium after $500 \mu \mathrm{M}$ isopropyl- $\beta$-D-thiogalactopyranoside induction for $4 \mathrm{~h}$ at $37^{\circ} \mathrm{C}$. Then, the cells were collected by centrifugation and resuspended in lysis buffer (PBS, TritonX-100 $1 \% \mathrm{v} / \mathrm{v}$, lysozyme $0.2 \mu \mathrm{g} / \mathrm{ml}$, DTT $2 \mathrm{mM}$ y protease inhibitors PMSF $1 \mathrm{mM}$, aprotinin $10 \mu \mathrm{g} / \mathrm{ml}$ y leupeptin $10 \mu \mathrm{g} / \mathrm{ml}$ ). After incubation of the cell suspension at $4^{\circ} \mathrm{C}$ for $30 \mathrm{~min}$, it was sonicated (Misonic XL2010), and centrifuged at 30,000 $\times \mathrm{g}$ at $4^{\circ} \mathrm{C}$ for $30 \mathrm{~min}$. The supernatants were purified on $200 \mu \mathrm{l}$ of GSH-agarose beads (GE Healthcare Life Sciences) at $4{ }^{\circ} \mathrm{C}$ for $2 \mathrm{~h}$ and stored at $-80^{\circ} \mathrm{C}$. GST-fused proteins $(10 \mu l)$ were incubated with $100 \mathrm{ng}$ of the recombinant p35/Cdk5 protein complex (Cell Signaling Technology). For input, gels were stained with Coomassie blue solution $(0.1 \%(\mathrm{w} / \mathrm{v})$ Coomassie blue, $50 \%$ (v/v) methanol, 10\% (v/v) acetic acid) for 15 min under stirring at room temperature, and then faded in a solution containing $20 \%(\mathrm{v} / \mathrm{v})$ methanol and $10 \%(\mathrm{v} / \mathrm{v})$ acetic acid with shaking.

Quantitative reverse transcription-polymerase chain reaction analysis. This was performed in total RNA samples, purified from neurons or astrocytes using a commercially available kit (Sigma), utilizing the Power SYBR Green RNA-to- $C_{T}$ 1-Step kit (Applied Biosystems, Township, USA). Reverse transcription was performed for $30 \mathrm{~min}$ at $48^{\circ} \mathrm{C}$, and PCR conditions were $10 \mathrm{~min}$ at $95^{\circ} \mathrm{C}$ followed by 40 cycles of $15 \mathrm{~s}$ at $95^{\circ} \mathrm{C}$ plus 1 min at $55^{\circ} \mathrm{C}$ using the following forward and reserve primers, respectively (Thermo Scientific, Offenbach, Germany), 5'-GCAGGACATGGATTTGATTGA-3' and 5'-GTCAAACACTTCTCGACTTAC-3' (Nrf2), 5'-GGAGCAATAAGAAATGCTTGCCA-3' and 5'-GGAGCCTCAAAATCTTC CTCATA-3' (Cul3), 5'-AGCACAGGGTGACAGAAGAG-3' and 5'-GAGGGACTC TGGTCTTTGTG-3' (GClc), 5'-GGCACAAGGACGTGCTCAAGT-3' and 5'-TGCA GAGTTTCAAGAACATCG-3' (Ho-1), 5'-GGGGACATGAACGTCATTCTCT-3' and 5'-AAGACCTGGAAGCCACAGAAGC-3' (Nq01), 5'-ACCAGCAGTTTCAGGAACC ATTT-3' and 5'-GCGCCAAGATTCACCTTCCCT-3' (Cop9S5), 5'-GCTTTCTGA CAAGGAGCAGCTTC-3' and 5'-CCACTGGAAGCTGGAGGGAGTT-3' (Cand1), 5'-GGGTGTGAACCACGAGAAAT-3' and 5'-CCTTCCACGATGCCAAAGTT-3' (Gapdh). The mRNA abundance of each transcript was normalized to the Gapdh mRNA abundance obtained in the same sample. The relative mRNA levels were calculated using the $\Delta \Delta C$ method, and were expressed as the fold change between sample and calibrator.

Reverse transcription and polymerase chain reaction (RT-PCR). Total RNA was purified from neurons and astrocytes using a commercially available kit (Sigma, Saint Louis, MO, USA). NR1, NR2A and NR2B mRNA expression were analyzed by electrophoresis in $4 \%$ agarose gel after RT-PCR, using the following forward and reverse oligonucleotides, respectively: $5^{\prime}$-CTGCTGACATTCG CCCTGCTT-3' and 5'-ATCTCAAACCAGACGCTGGACT-3' for NR1, 5'-CTCA TCCCCAAAGAGTTTCCATC-3' and 5'-CCTATCATTCCATTCCACACATTG-3' for NR2A, 5'-CCTTTCCGCTTTGGGACTGTG-3' and 5'-GTTCTTCCATCTCCCCA TCTCCA for NR2B and 5'-GGGTGTGAACACGAGAAAT-3' and 5'-CCTTCCACG ATGCCAAAGTT- $3^{\prime}$ for GAPDH. Reverse transcription was performed at $48^{\circ} \mathrm{C}$ for $50 \mathrm{~min}$, and PCR conditions were $10 \mathrm{~min}$ at $95^{\circ} \mathrm{C}, 35$ cycles of $30 \mathrm{~s}$ at $95^{\circ} \mathrm{C}, 30 \mathrm{~s}$ at $52^{\circ} \mathrm{C}$ and $1 \mathrm{~min}$ at $72{ }^{\circ} \mathrm{C}$. Final extension was carried out for $10 \mathrm{~min}$ at $72^{\circ} \mathrm{C}$. In no case was a band detected by PCR without reverse transcription.

Epifluorescence microscopy. Astrocytes grown on glass coverslips were transfected and treated as indicated. Then, the cells were fixed with 4\% (v/v in PBS) paraformaldehyde for $20 \mathrm{~min}$ and incubated with DAPI ( $30 \mu \mathrm{M}$; Sigma). Coverslips were washed and mounted in SlowFade light antifade reagent (Molecular Probes, Eugene, OR, USA) on glass slides for fluorescence microphotographs at $\times 40$ magnification using a Nikon Eclipse Ti-E (Tokyo, Japan). Approximately $150 \mathrm{GFP}^{+}$ $\mathrm{DAPl}^{+}$nuclei were quantified in at least five microscopic fields.

Inmunocytochemistry. Cells grown on glass coverslips were fixed with $4 \%$ paraformaldehyde ( $\mathrm{v} / \mathrm{v}$ in PBS) for $10 \mathrm{~min}$, rinsed with PBS and permeabilized for 5 min with $0.2 \%$ Triton- $X-100$. Cells were then incubated for $1 \mathrm{~h}$ at room temperature in PBS containing blocking solution $(0.2 \%$ Triton- $\mathrm{X}-100,5 \%$ goat serum, bovine serum albumin (BSA) $1 \%$ ) and kept overnight at $4{ }^{\circ} \mathrm{C}$ with anti-GFAP (1:250 dilution), anti-Map2 (1/500 dilution) anti-lba-1 (1:250 dilution; Wako, 019-19741) and anti-04 (1:150 dilution; Millipore, MAB345). After washing with PBS, cells were incubated with the secondary antibodies Alexa-488-conjugated goat anti-rabbit (1:500 dilution; Molecular Probes, Invitrogen), Alexa 594-conjugated goat anti-mouse (1:500 dilution; Molecular Probes, Invitrogen), Cy2-conjugated goat anti-mouse (1:500 dilution; Jackson ImmunoResearch Laboratories, West Grove, PA, USA) and Cy3-conjugated goat anti-rabbit (1:500 dilution; Jackson ImmunoResearch Laboratories) for $1 \mathrm{~h}$ at room temperatura, followed by DAPI ( $30 \mu \mathrm{M}$; Sigma) staining. Coverslips were washed and mounted in SlowFade light antifade reagent (Molecular Probes) on glass slides for fluorescence microphotographs at $\times 40$ magnification using a Nikon Inverted microscope (Eclipse Ti-E, Tokyo, Japan). For the assessment of $\mathrm{GFP}^{+}$nuclear localization, astrocytes were fixed, mounted and stained with DAPI as above for fluorescence microphotographs (x40 magnification). Approximately $150 \mathrm{GFP}^{+} / \mathrm{DAPI}^{+}$nuclei were quantified in at least five microscopic fields.

Protein determinations. Cells were lysed in $0.1 \mathrm{M} \mathrm{NaOH}$ and used for the determination of protein concentrations by either the Lowry method ${ }^{55}$ or the BCA 
protein assay kit (Pierce) following the manufacturer's instructions, using BSA as standard.

Statistical analysis. All measurements in were carried out at least in three different culture preparations, and the results are expressed as the mean values \pm S.E.M. For the comparisons between two groups of values, the statistical analysis of the results was performed by the Student's t-test. For multiple values comparisons, we used one-way ANOVA (analysis of variance) followed by Bonferroni test. The statistical analysis was performed using the SPSS 16.0 software (Statiscal Package for the Social Sciences, Madrid, Spain) for Macintosh. In all cases, $P<0.05$ was considered significant.

\section{Conflict of Interest}

The authors declare no conflict of interest.

Acknowledgements. The technical assistances of Ms Monica Carabias and Ms Monica Resch are acknowledged. AG is funded by Junta de Extremadura-FEDER (GR10010). DJ-B is the recipient of a FIS Fellowship. PS-C was granted a fellowship from Gobierno de Extremadura (PD10058; Consejería de Empleo, Empresa e Innovación) and European Social Fund. This work was funded by the Spanish Ministerio de Economia y Competitividad (to JPB, grant number SAF2013-41177-R), the Instituto de Salud Carlos III (to JPB, grant number RD12/0043/0021; to AA, grant numbers PI12/00685 and RD12/0014/0007), Junta de Castilla y Leon (to JPB, SA003U13), the SP3-People-MC-ITN program of the European Commission (to JPB, 608381 TINTIN), the National Institutes of Drug Abuse/National Institutes of Health (NIH/NIDA) (to JPB, 1R21DA037678-01) and the European Regional Development Fund.

\section{Author contributions}

JPB conceived the idea and planned the experiments. JPB, DJ-B, PS-C, AG and AA designed and performed research and analyzed the data. JPB wrote the manuscript.

1. Bossy-Wetzel E, Schwarzenbacher R, Lipton SA. Molecular pathways to neurodegeneration. Nat Med 2004; 10: S2-S9.

2. Hardingham GE, Bading $H$. Synaptic versus extrasynaptic NMDA receptor signalling: implications for neurodegenerative disorders. Nat Rev Neurosci 2010; 11: 682-696.

3. Vaughn AE, Deshmukh M. Glucose metabolism inhibits apoptosis in neurons and cancer cells by redox inactivation of cytochrome c. Nat Cell Biol 2008; 10: 1477-1483.

4. Herrero-Mendez A, Almeida A, Fernandez E, Maestre C, Moncada S, Bolanos JP. The bioenergetic and antioxidant status of neurons is controlled by continuous degradation of a key glycolytic enzyme by APC/C-Cdh1. Nat Cell Biol 2009; 11: 747-752.

5. Papadia S, Soriano FX, Leveille F, Martel MA, Dakin KA, Hansen HH et al. Synaptic NMDA receptor activity boosts intrinsic antioxidant defenses. Nat Neurosci 2008; 11: 476-487.

6. Maestre C, Delgado-Esteban M, Gomez-Sanchez JC, Bolanos JP, Almeida A. Cdk5 phosphorylates Cdh1 and modulates cyclin B1 stability in excitotoxicity. Embo J 2008; 27: 2736-2745.

7. Rodriguez-Rodriguez P, Fernandez E, Almeida A, Bolanos JP. Excitotoxic stimulus stabilizes PFKFB3 causing pentose-phosphate pathway to glycolysis switch and neurodegeneration. Cell Death Differ 2012; 19: 1582-1589.

8. Rothstein JD, Dykes-Hoberg M, Pardo CA, Bristol LA, Jin L, Kunci RW et al. Knockout of glutamate transporters reveals a major role for astroglial transport in excitotoxicity and clearance of glutamate. Neuron 1996; 16: 675-686.

9. Pellerin L, Magistretti PJ. Glutamate uptake into astrocytes stimulates aerobic glycolysis: a mechanism coupling neuronal activity to glucose utilization. Proc Natl Acad Sci USA 1994; 91: 10625-10629.

10. Bouzier-Sore AK, Voisin P, Canioni P, Magistretti PJ, Pellerin L. Lactate is a preferential oxidative energy substrate over glucose for neurons in culture. J Cereb Blood Flow Metab 2003; 23: 1298-1306.

11. Allaman I, Belanger M, Magistretti PJ. Astrocyte-neuron metabolic relationships: for better and for worse. Trends Neurosci 2011; 34: 76-87.

12. Dringen R, Pfeiffer $B$, Hamprecht $B$. Synthesis of the antioxidant glutathione in neurons: supply by astrocytes of CysGly as precursor for neuronal glutathione. J Neurosci 1999; 19: 562-569.

13. Hayes JD, McMahon M. NRF2 and KEAP1 mutations: permanent activation of an adaptive response in cancer. Trends Biochem Sci 2009; 34: 176-188.

14. Habas A, Hahn J, Wang $X$, Margeta M. Neuronal activity regulates astrocytic Nrf2 signaling. Proc Natl Acad Sci USA 2013; 110: 18291-18296.

15. Deighton RF, Markus NM, Al-Mubarak B, Bell KF, Papadia S, Meakin PJ et al. Nrf2 target genes can be controlled by neuronal activity in the absence of Nrf2 and astrocytes. Proc Natl Acad Sci USA 2014; 111: E1818-E1820.
16. Habas A, Hahn J, Wang X, Margeta M. Reply to Deighton et al.: neuronal activity regulates distinct antioxidant pathways in neurons and astrocytes. Proc Natl Acad Sci U S A 2014; 111: E1821-E1822.

17. Haskew-Layton RE, Payappilly JB, Smirnova NA, Ma TC, Chan KK, Murphy TH et al. Controlled enzymatic production of astrocytic hydrogen peroxide protects neurons from oxidative stress via an Nrf2-independent pathway. Proc Natl Acad Sci USA 2010; 107: $17385-17390$.

18. Bell KF, Al-Mubarak B, Fowler JH, Baxter PS, Gupta K, Tsujita T et al. Mild oxidative stress activates Nrf2 in astrocytes, which contributes to neuroprotective ischemic preconditioning. Proc Natl Acad Sci USA 2011; 108: E1-E2 author reply E3-4.

19. Verkhratsky A, Kirchhoff F. NMDA Receptors in glia. Neuroscientist 2007; 13: 28-37.

20. Zhou C, Wee S, Rhee E, Naumann M, Dubiel W, Wiolf DA. Fission yeast COP9/signalosome suppresses cullin activity through recruitment of the deubiquitylating enzyme Ubp12p. Mol Cell 2003; 11: 927-938.

21. Lo SC, Hannink M. CAND1-mediated substrate adaptor recycling is required for efficient repression of Nrf2 by Keap1. Mol Cell Biol 2006; 26: 1235-1244.

22. Seifert G, Steinhäuser C. Ionotropic glutamate receptors in astrocytes. Prog Brain Res 2001; 132: 287-299.

23. Conti F, DeBiasi S, Minelli A, Melone M. Expression of NR1 and NR2A/B subunits of the NMDA receptor in cortical astrocytes. Glia 1996; 17: 254-258.

24. Schipke C, Ohlemeyer C, Matyash M, Nolte C, Kettenmann H, Kirchhoff F. Astrocytes of the mouse neocortex express functional $\mathrm{N}$-methyl-D-aspartate receptors. Faseb $\mathrm{J} 2001 ; 15$ : 1270-1272.

25. Lee M, Ting K, Adams S, Brew B, Chung R, Guillemin G. Characterisation of the expression of NMDA receptors in human astrocytes. PLos One 2010; 5: e14123.

26. Wroge CM, Hogins J, Eisenman L, Mennerick S. Synaptic NMDA receptors mediate hypoxic excitotoxic death. J Neurosci 2012; 32: 6732-6742.

27. Palygin O, Lalo U, Pankratov Y. Distinct pharmacological and functional properties of NMDA receptors in mouse cortical astrocytes. Br J Pharmacol 2011; 163: 1755-1766.

28. Kusakawa G, Saito T, Onuki R, Ishiguro K, Kishimoto T, Hisanaga S. Calpain-dependent proteolytic cleavage of the p35 cyclin-dependent kinase 5 activator to p25. J Biol Chem 2000; 275: 17166-17172.

29. Hisanaga S, Endo R. Regulation and role of cyclin-dependent kinase activity in neuronal survival and death. J Neurochem 2010; 115: 1309-1321.

30. Zhao CT, Li K, Li JT, Zheng W, Liang XJ, Geng AQ et al. PKCdelta regulates cortical radial migration by stabilizing the Cdk5 activator p35. Proc Natl Acad Sci USA 2009; 106 : 21353-21358.

31. Agarwal ML, Larkin HE, Zaidi SI, Mukhtar H, Oleinick NL. Phospholipase activation triggers apoptosis in photosensitized mouse lymphoma cells. Cancer Res 1993; 53: 5897-5902.

32. Susarla BT, Robinson MB. Rottlerin, an inhibitor of protein kinase Cdelta (PKCdelta), inhibits astrocytic glutamate transport activity and reduces GLAST immunoreactivity by a mechanism that appears to be PKCdelta-independent. J Neurochem 2003; 86: 635-645.

33. Dringen R, Kranich $\mathrm{O}$, Hamprecht B. The g-glutamyltranspeptidase inhibitor acivicin preserves glutathione released by astroglial cells in culture. Neurochem Res 1997; 22: 727-733.

34. Fernandez-Fernandez S, Almeida A, Bolanos JP. Antioxidant and bioenergetic coupling between neurons and astrocytes. Biochem J 2012; 443: 3-11.

35. Kikkawa U, Matsuzaki H, Yamamoto $\mathrm{T}$. Protein kinase $\mathrm{C}$ delta (PKC delta): activation mechanisms and functions. J Biochem 2002; 132: 831-839.

36. Young KW, Garro MA, Challiss RA, Nahorski SR. NMDA-receptor regulation of muscarinicreceptor stimulated inositol 1,4,5-trisphosphate production and protein kinase $\mathrm{C}$ activation in single cerebellar granule neurons. J Neurochem 2004; 89: 1537-1546.

37. Bloom DA, Jaiswal AK. Phosphorylation of Nrf2 at Ser40 by protein kinase $\mathrm{C}$ in response to antioxidants leads to the release of Nrf2 from INrf2, but is not required for Nrf2 stabilization/ accumulation in the nucleus and transcriptional activation of antioxidant response elementmediated NAD(P)H:quinone oxidoreductase-1 gene expression. J Biol Chem 2003; 278: 44675-44682.

38. Araque A, Carmignoto G, Haydon PG, Oliet SH, Robitaille R, Volterra A. Gliotransmitters travel in time and space. Neuron 2014; 81: 728-739.

39. Pellerin L, Pellegri G, Bittar PG, Charnay Y, Bouras C, Martin JL et al. Evidence supporting the existence of an activity-dependent astrocyte-neuron lactate shuttle. Dev Neurosci 1998; 20: 291-299.

40. Pellerin L, Bouzier-Sore AK, Aubert A, Serres S, Merle M, Costalat R et al. Activitydependent regulation of energy metabolism by astrocytes: an update. Glia 2007; 55: 1251-1262.

41. Yang J, Ruchti E, Petit JM, Jourdain P, Grenningloh G, Allaman I et al. Lactate promotes plasticity gene expression by potentiating NMDA signaling in neurons. Proc Natl Acad Sci USA 2014; 111: 12228-12233.

42. DeNicola GM, Karreth FA, Humpton TJ, Gopinathan A, Wei C, Frese K et al. Oncogeneinduced Nrf2 transcription promotes ROS detoxification and tumorigenesis. Nature 2011; 475: 106-109.

43. Jaramillo MC, Zhang DD. The emerging role of the Nrf2-Keap1 signaling pathway in cancer. Genes Dev 2013; 27: 2179-2191.

44. Liang Q, Li L, Zhang J, Lei Y, Wang L, Liu DX et al. CDK5 is essential for TGF-beta1-induced epithelial-mesenchymal transition and breast cancer progression. Sci Rep 2013; 3: 2932. 
45. Almeida A, Moncada S, Bolaños JP. Nitric oxide switches on glycolysis through the AMP protein kinase and 6-phosphofructo-2-kinase pathway. Nat Cell Biol 2004; 6: 45-51.

46. Zheng YL, Li BS, Kanungo J, Kesavapany S, Amin N, Grant P et al. Cdk5 Modulation of mitogen-activated protein kinase signaling regulates neuronal survival. Mol Biol Cell 2007; 18: 404-413.

47. Ohtsuka T, Ryu H, Minamishima YA, Macip S, Sagara J, Nakayama KI et al. ASC is a Bax adaptor and regulates the p53-Bax mitochondrial apoptosis pathway. Nat Cell Biol 2004; 6 121-128.

48. Almeida A, Bolaños JP. A transient inhibition of mitochondrial ATP synthesis by nitric oxide synthase activation triggered apoptosis in primary cortical neurons. J Neurochem 2001; 77 : 676-690.

49. Dos-Anjos S, Martínez-Villayandre B, Montori S, Regueiro-Purriños M, Gonzalo-Orden J, Fernández-López A. Transient global ischemia in rat brain promotes different NMDA receptor regulation depending on the brain structure studied. Neurochem Int 2009; 54: 180-185.
50. Salazar M, Pariente JA, Salido GM, Gonzalez A. Ebselen increases cytosolic free $\mathrm{Ca}^{2+}$ concentration, stimulates glutamate release and increases GFAP content in rat hippocampal astrocytes. Toxicology 2008; 244: 280-291.

51. Grynkiewicz G, Poenie M, Tsien RY. A new generation of $\mathrm{Ca} 2+$ indicators with greatly improved fluorescence properties. J Biol Chem 1985; 260: 3440-3450.

52. Tietze F. Enzyme method for quantitative determination of nanogram amounts of total and oxidized glutathione: application to mammalian blood and other tissues. Anal Biochem 1969; 27: 502-522.

53. Foo LC. Purification of rat and mouse astrocytes by immunopanning. Cold Spring Harb Protoc 2013; 2013: 421-432.

54. Wang J, Liu S, Fu Y, Wang JH, Lu Y. Cdk5 activation induces hippocampal CA1 cell death by directly phosphorylating NMDA receptors. Nat Neurosci 2003; 6: 1039-1047.

55. Lowry OH, Rosebrough NJ, Lewis-Farr A, Randall RJ. Protein measurement with the Folin phenol reagent. J Biol Chem 1951; 193: 265-275.

\section{Supplementary Information accompanies this paper on Cell Death and Differentiation website (http://www.nature.com/cdd)}

